Sharif University of Technology
Scientia Iranica
Transactions E: Industrial Engineering
http://scientiairanica.sharif.edu

\title{
A joint determination of production cycle length, maintenance policy, and control chart parameters considering time value of money under stochastic shift size
}

\author{
A. Salmasnia*, Z. Hajihosseini, M. Namdar, and F. Mamashli \\ Department of Industrial Engineering, Faculty of Engineering and Technology, University of Qom, Qom, Iran.
}

Received 10 December 2017; received in revised form 20 May 2018; accepted 16 July 2018

\author{
KEYWORDS \\ Production cycle \\ length; \\ Maintenance policy; \\ Time value of money; \\ Variable sampling \\ interval; \\ Stochastic shift size; \\ Economic-statistical \\ design.
}

\begin{abstract}
Statistical process monitoring, maintenance policy, and production cycle length are usually investigated separately, while they are three dependent aspects in the industrial systems. Moreover, most of the papers that have integrated these aspects simultaneously suffer from three major drawbacks as follows: (1) optimizing the production cost without considering the time value of money to simplify the model; (2) considering the fixed shift size while it is a random variable in the real condition; and (3) economic design of control charts ignoring the statistical properties that lead to a decrease in the control chart power, extremely. To eliminate these weaknesses, this paper presents an integrated model of production cycle length, maintenance policy, and economic-statistical design, considering the time value of money and the stochastic shift size. Furthermore, to maintain the reliability of the system at an acceptable level, the presented model uses non-uniform sampling. Finally, three comparative studies on the main contributions are presented to illustrate the advantages of the model, and sensitivity analysis is implemented on several parameters to extend insights into the matter.
\end{abstract}

(C) 2020 Sharif University of Technology. All rights reserved.

\section{Introduction}

Quickly changing markets and the extension of product variety have increased the need for advanced equipment. They should be maintained in a suitable operational condition to achieve the best output of production processes. Statistical Process Monitoring (SPM) and maintenance policy are two common tools to increase the proportion of conforming products in

\footnotetext{
*. Corresponding author. Tel.: 982532103585

E-mail addresses: a.salmasnia@qom.ac.ir (A. Salmasnia);

z.hajihosseini@stu.qom.ac.ir (Z.Hajihosseini);

mr.namdar@stu.qom.ac.ir (M.Namdar);

Faezemamashli@yahoo.com (F. Mamashli)
}

such production systems. Therefore, the production run length, maintenance policy, and SPM are three dependent issues. Performing the maintenance activities increases the interval between the occurrence of two assignable causes and reduces the production rate of non-conforming items. In other words, the level of the on-hand inventory increases by performing maintenance activities [1]. Ben-Daya [2] expressed that the Preventive Maintenance (PM) activities significantly reduced the quality control costs so that the total imposed cost on the system decreased in comparison to the no-PM case. Consequently, it appears necessary to develop approaches that consider the interdependency among the three mentioned concepts in the manufacturing processes. In spite of the mentioned facts, most researchers have considered these three concepts 
separately in the literature. For instance, Cheng et al. [3], Zhou et al. [4], and Costa and Rahim [5] studied $\mathrm{EPQ}$, maintenance policy, and SPM in their papers, respectively.

To improve the performance of the manufacturing process, researchers developed the joint models that include two of the three mentioned concepts in recent years. In this regard, Gan et al. [6] focused on the interaction among maintenance, buffer inventory, and spare parts inventory to minimize the long-term expected cost of a manufacturing system. Wen et al. [7] integrated predictive maintenance with the traditional EPQ model, in which the autoregressive integrated moving average model was adopted to predict the system's healthy indicator. In addition, Rahim and Ben-Daya [8] presented a joint model of EPQ and designed the control chart, in which the effects of both deteriorating product and deteriorating production process on EPQ model were investigated. Cheng and Chou [9] analyzed a real-time inventory decision system considering special rules, such as Western Electric rules, to detect the out-of-control state. Xiang [10] proposed a joint model of SPM and PM for a Markovian deterioration process. In the same context, $\mathrm{Wu}$ and Makis [11] designed a chi-square control chart for the condition-based maintenance. Moreover, several other papers such as Makis and Fung [12], and Jiang et al. [13] were conducted on integrating the two of the three mentioned concepts.

Although considering the three mentioned concepts concurrently has a significant role in decreasing the expected costs of a production system [14], only a few studies in the literature analyzed them simultaneously. For example, Bouslah et al. [15] considered production run length, maintenance policy, and SPM in a unified model in which the quality deteriorated over time. Lin et al. [16] proposed an integrated model of inventory and PM for an imperfect process with minimal repair, rework, and PM error. Beheshti Fakher et al. [17] presented a capacitated lot-sizing problem with imperfect maintenance for the multi-product systems. They considered a production system with parallel machines that deteriorate over time. Moreover, Ben-Daya and Makhdoum [18] and Nourelfath et al. [19] are the other studies that have been implemented in this context.

Although the time value of money is an important financial concept for analyzing costs, there are only a few studies that considered this concept in analyzing the production system cost. In this context, Luciano and Peccati [20] discussed the application of the adjusted present value approaches to an inventory problem considering the equity or debt financing. Van der Laan [21] analyzed the effect of Net Present Value (NPV) on a stochastic inventory model that was integrated with manufacturing and re-manufacturing activities. Applying Laplace transforms, Disney et al. [22] extended the EPQ model by analyzing cash flows from the NPV viewpoint. Several other authors such as Lin et al. [23] and Beullens and Janssens [24] proposed the particular mathematical models based on NPV technique and financing concepts.

It is obvious that the control charts are one of the most practical tools for the statistical process monitoring. The economic and economic-statistical approaches are two common ways of designing control charts. Since the Economic Design (ED) of the control charts ignores statistical properties, it is evident that the Economic-Statistical Design (ESD) leads to more powerful control charts. Duncan [25] proposed the first ED model for an $X$-bar control chart. Afterward, the ESD was first proposed by Saniga [26]; then, other authors such as Nenes et al. [27] and Yin et al. [28] applied this approach to the design of control charts.

More papers that presented the integrated model of inventory, maintenance, and control chart employed the fixed sampling interval from the process. For example, Makis and Fung [12] investigated the effect of machine failures on the optimal lot size in a production process, while they assumed that sampling intervals were fixed. Pan et al. [29] presented a joint EPQ model based on a Shewhart chart for an imperfect manufacturing process with a fixed sampling interval. In contrast to the mentioned studies, there are a few researchers that considered variable sampling interval in their studies. In this regard, Salmasnia et al. [30] calculated the sampling intervals such that the expected number of system failures was an identical value at different intervals. Moreover, in the study of BenDaya [2], the sampling intervals were determined such that the integrated failure rate for all intervals was the same.

In addition, to relax the calculations, most studies have considered a fixed shift size when an assignable cause occurs in the process in spite of the random essence of the shift size in the real industrial environment. In this regard, Wu et al. [31] and Celano et al. [32] are two of the few studies that investigated the probability distribution of the random process shifts, and Celano et al. [32] developed a stochastic shift model for the ED of control charts. At the end of this section, Table 1 summarizes the properties of the existing papers in the literature.

To bridge the existing gaps in the literature, this study proposes a unified mathematical model that integrates the concepts of production cycle length, maintenance policy, and designing the control chart. Further, the suggested model in contrast to the other approaches in this field optimizes NPV of manufacturing costs as one of the common methods for considering the time value of money subject to statistical constraints. These costs include the quality loss cost, 
Table 1. Summarized literature review.

\begin{tabular}{|c|c|c|c|c|c|c|c|}
\hline \multirow[b]{2}{*}{ Papers } & \multirow[b]{2}{*}{ Integrated concepts } & \multicolumn{2}{|c|}{$\begin{array}{c}\text { Type of } \\
\text { design }\end{array}$} & \multicolumn{2}{|c|}{$\begin{array}{c}\text { Sampling } \\
\text { interval }\end{array}$} & \multirow{2}{*}{$\begin{array}{l}\text { Time value } \\
\text { of money }\end{array}$} & Shift size \\
\hline & & $\mathbf{E D}^{\mathrm{a}}$ & $\mathbf{E S D}^{\mathrm{b}}$ & Fixed & Vriable & & Fixed Random \\
\hline Cheng and Chou [9] & Inventory/SPM & & $\sqrt{ }$ & $\sqrt{ }$ & & & $\sqrt{ }$ \\
\hline Lin et al. [16] & Maintenance/inventory/SPM & & & & $\sqrt{ }$ & & $\sqrt{ }$ \\
\hline Xiang [10] & Maintenance/SPM & & $\sqrt{ }$ & $\sqrt{ }$ & & & $\sqrt{ }$ \\
\hline Wu et al. [31] & SPM & & $\sqrt{ }$ & $\sqrt{ }$ & & & $\sqrt{ }$ \\
\hline Beheshti Fakher et al. [17] & Maintenance/inventory/SPM & & & & $\sqrt{ }$ & & $\sqrt{ }$ \\
\hline Lin et al. [23] & Inventory & & & & & $\sqrt{ }$ & \\
\hline Pan et al. [29] & Maintenance/inventory/SPM & & $\sqrt{ }$ & $\sqrt{ }$ & & & $\sqrt{ }$ \\
\hline Nenes et al. [27] & SPM & & $\sqrt{ }$ & & $\sqrt{ }$ & & $\sqrt{ }$ \\
\hline Duncan [25] & SPM & $\sqrt{ }$ & & $\sqrt{ }$ & & & $\sqrt{ }$ \\
\hline Zhou et al. [4] & Maintenance & & & & & & \\
\hline Disney et al. [22] & Inventory & & & & & $\sqrt{ }$ & \\
\hline Makis and Fung [12] & Inventory/SPM & & & $\sqrt{ }$ & & & $\sqrt{ }$ \\
\hline Salmasnia et al. [30] & Maintenance/inventory/SPM & & $\sqrt{ }$ & & $\sqrt{ }$ & & $\sqrt{ }$ \\
\hline Ben Daya and Makhdoum [18] & Maintenance/inventory/SPM & $\sqrt{ }$ & & & $\sqrt{ }$ & & $\sqrt{ }$ \\
\hline Wen et al. [7] & Maintenance/inventory & & & & & & \\
\hline Van der Laan [21] & Inventory & & & & & $\sqrt{ }$ & \\
\hline Saniga [26] & SPM & & $\sqrt{ }$ & $\sqrt{ }$ & & & $\sqrt{ }$ \\
\hline Rahim and Ben-Daya [8] & Inventory/SPM & $\sqrt{ }$ & & & $\sqrt{ }$ & & $\sqrt{ }$ \\
\hline Cheng et al. [3] & Inventory & & & & & & \\
\hline Costa and Rahim [5] & SPM & $\sqrt{ }$ & & & $\sqrt{ }$ & & $\sqrt{ }$ \\
\hline Beullens and Janssens [24] & Inventory & & & & & $\sqrt{ }$ & \\
\hline Nourelfath et al. [19] & Maintenance/inventory/SPM & & & & $\sqrt{ }$ & & $\sqrt{ }$ \\
\hline Jiang et al. [13] & Maintenance/inventory & & & & & & \\
\hline Bouslah et al. [15] & Maintenance/inventory/SPM & & & $\sqrt{ }$ & & & $\sqrt{ }$ \\
\hline Celano et al. [32] & SPM & $\sqrt{ }$ & & $\sqrt{ }$ & & & $\sqrt{ }$ \\
\hline Luciano and Peccati [20] & Inventory & & & & & $\sqrt{ }$ & \\
\hline Wu and Makis [11] & Maintenance/SPM & & $\sqrt{ }$ & $\sqrt{ }$ & & & $\sqrt{ }$ \\
\hline Gan et al $[6]$ & Maintenance/inventory & & & & & & \\
\hline Ben-Daya [2] & Maintenance/inventory/SPM & $\sqrt{ }$ & & & $\sqrt{ }$ & & $\sqrt{ }$ \\
\hline Yin et al. [28] & Maintenance/ SPM & & $\sqrt{ }$ & $\sqrt{ }$ & & & $\sqrt{ }$ \\
\hline This paper & Maintenance/inventory/SPM & & $\sqrt{ }$ & & $\sqrt{ }$ & $\sqrt{ }$ & $\sqrt{ }$ \\
\hline
\end{tabular}

${ }^{\mathrm{a}} \mathrm{ED}$ : Economic Design; ${ }^{\mathrm{b}} \mathrm{ESD}$ : Economic-Statistical Design.

the sampling cost, the maintenance cost, the inventory holding cost, and the setup cost. Moreover, this model considers the shift size as a random variable to make the model more adaptable to the real production situation and determines the sampling intervals such that the expected number of system failures is the same value for all intervals.

The following sections of this research are struc- tured as follows: Firstly, in the next section, the problem definition is described. Then, the applied notations and assumptions in the problem are introduced in Sections 2.1 and 2.2, respectively. In Section 3, the model description including the calculation of objective function and constraints is explained. Section 4 expresses a solution approach for optimizing the suggested model. Then, to indicate the applicability of 
the proposed model, a numerical example based on a case study is investigated in Section 5. In addition, three comparative studies and sensitive analysis are presented in this section. Finally, in Section 6, the conclusions and the suggestions for further research studies are presented.

\section{Problem definition}

The classical studies have focused on the manufacturing problem with this assumption that the process operates in a perfect condition, meaning that all of the products are flawless. However, the process in the real industrial environments may deteriorate with time and produce defective items due to a number of factors such as human mistake, fatigue machine, etc. This paper investigates an imperfect manufacturing system that can operate in the in-control or out-of-control states. The manufacturing system begins its operation from the in-control state and, over time, may shift to the outof-control state due to the occurrence of an assignable cause. An $X$-bar Shewhart chart is applied to inform operators when the process shifts to the out-of-control state. The production system stops when the control chart issues a true alarm; otherwise, it continues to produce items.

In this model, the sampling is performed at times $t_{1}, t_{2}, \ldots, t_{m}$, and PM activities are synchronized with the sampling. This maintenance policy is applied according to Ben-Daya [2] for decreasing the hazard rate and rejuvenating the production process, as illustrated in Figure 1. To be specific, the process pauses its operation at the pre-determined times $\left\{t_{l}, t_{2 l}, t_{3 l}, \ldots\right\}$ as a subset of $\left\{t_{1}, t_{2}, \ldots, t_{m}\right\}$ to carry out the PM actions. In fact, both PM activity and sampling are implemented in parallel with frequency $l$.

This study in contrast to most of the previous papers integrates production cycle length, SPM, and maintenance concepts into a unified model. Moreover, the presented mathematical model sets sampling intervals such that the integrated failure rate over all

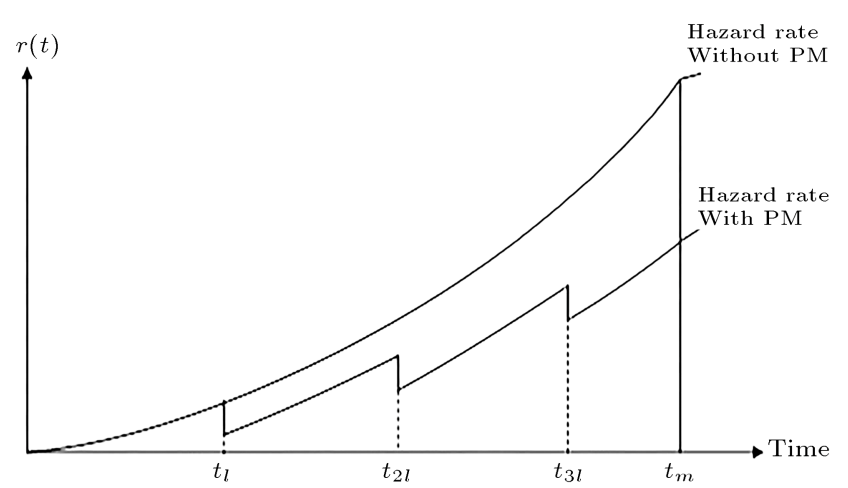

Figure 1. Effect of Preventive Maintenance (PM) activities on the hazard rate. sampling intervals is the same value. The purpose of the proposed model is to minimize the cost of the manufacturing system that is subject to the statistical constraints. To make the model results more adaptable to the actual cost imposed on the manufacturer, this study considers the time value of money for calculating the system costs consisting of: (1) the setup cost, (2) the inventory holding cost, (3) the maintenance cost, (4) the sampling cost, and (5) the quality loss cost. According to the above-mentioned descriptions, the graphical representation of the cost structure is illustrated in Figure 2.

\subsection{Notations}

In this subsection, the notations are introduced in Table 2, separately. These are divided into five parts: indices, decision variables, time parameters, cost parameters, and process parameters.

\subsection{Assumptions and definitions}

The considered assumptions in the proposed model are as follows:

1. Quality characteristic has a normal distribution function with the target value, $\mu_{0}$, and standard deviation, $\sigma$.

2. The occurrence of an assignable cause leads to a change in the process mean from $\mu_{0}$ to $\mu_{1}=\mu_{0} \pm \delta \sigma$ without any changes in the variance.

3. The manufacturing process begins in the in-control state and may shift to the out-of-control state after a period of time. If the process is in the in-control state, the production continues until the next sampling; however, if an assignable cause occurs and is detected by the control chart, the process pauses until the accumulated on-hand inventory reaches zero.

4. The duration of the in-control period follows a Weibull distribution, in which the PDF, CDF, and hazard rate are defined by Eqs. (1)-(3), respectively:

$$
\begin{aligned}
& f(t)=\lambda \nu t^{\nu-1} e^{-\lambda t^{\nu}} \quad t, \lambda>0, \nu \geq 1, \\
& F(t)=e^{-\lambda t^{\nu}} \\
& r(t)=\frac{f(t)}{F(t)}=\frac{\lambda \nu t^{\nu-1} e^{-\lambda t^{\nu}}}{e^{-\lambda t^{\nu}}}=\lambda \nu t^{\nu-1}
\end{aligned}
$$

5. The process is monitored by an $X$-bar chart with sample size $n$ at times $t_{1}, t_{2}, t_{3}, \ldots, t_{m}$. Eq. (4) calculates the time of the $j$ th sampling $\left(t_{j}\right)$ for $j=1,2, . ., m, t_{0}=0$ where $h_{j}$ is the $j$ th sampling interval: 
Table 2. Notations.

\begin{tabular}{|c|c|}
\hline Notations & Description \\
\hline \multicolumn{2}{|l|}{ Indices: } \\
\hline$i, j, r, y$ & Indices of the sampling intervals \\
\hline$s$ & Index of Preventive Maintenance (PM) activities \\
\hline \multicolumn{2}{|c|}{ Decision variables: } \\
\hline$h_{1}$ & Length of the first sampling interval \\
\hline$k$ & Control limit coefficient of the $X$-bar chart \\
\hline$l$ & Frequency in which PM actions should be implemented \\
\hline$m$ & Number of sampling intervals \\
\hline$n$ & Sample size \\
\hline \multicolumn{2}{|c|}{ Process parameters: } \\
\hline$A$ & Quality loss index related to the specific control limit \\
\hline$A R L_{0}$ & Average run length when the process is in the in-control state \\
\hline$A R L_{1}$ & Average run length when the process is in the out-of-control state \\
\hline$A R L_{l}$ & Acceptable lower bound of $A R L_{0}$ \\
\hline$A R L_{u}$ & Acceptable upper bound of $A R L_{1}$ \\
\hline$D$ & Demand rate \\
\hline$f(x)$ & The normal density function of $x$ \\
\hline$f(\delta)$ & Density function of shift size \\
\hline$h_{l}$ & Lower bound for the first sampling interval \\
\hline$h_{u}$ & Upper bound for the first sampling interval \\
\hline$I_{j}$ & Expected inventory level at the end of the $j$ th interval \\
\hline$L C L$ & Lower control limit of the $X$-bar chart \\
\hline$m_{l}$ & Lower bound for the number of sampling intervals \\
\hline$n_{l}$ & Lower bound of sample size \\
\hline$n_{u}$ & Upper bound of sample size \\
\hline$P$ & Production rate \\
\hline$U C L$ & Upper control limit of the $X$-bar chart \\
\hline$x$ & Quality characteristic of the Taguchi function \\
\hline$\alpha$ & $\operatorname{Pr}$ (exceeding control limits | process is in control) \\
\hline$\beta$ & $\operatorname{Pr}($ not exceeding control limits | process is out of control) \\
\hline$\delta$ & Shift size when the process shifts to the out-of-control state \\
\hline$\Delta$ & Tolerance in the Taguchi function \\
\hline$\lambda$ & Scale parameter of the Weibull distribution \\
\hline$\mu_{0}$ & Process mean in the in-control state \\
\hline$\mu_{1}$ & Process mean in the out-of-control state \\
\hline$\mu_{\delta}$ & Mean of shift size \\
\hline$v$ & Shape parameter of the Weibull distribution \\
\hline$\sigma$ & Standard deviation of the quality characteristic \\
\hline \multicolumn{2}{|c|}{ Cost parameters: } \\
\hline$C_{f}$ & Fixed cost of sampling \\
\hline$C_{f a}$ & Cost of false alarm \\
\hline$C_{i}$ & Inventory holding cost per unit per time unit \\
\hline$C_{\text {in }}$ & Quality loss cost per time unit when the process is in the in-control state \\
\hline$C_{\text {out }}$ & Quality loss cost per time unit when the process is in the out-of-control state \\
\hline$C_{p m}$ & Cost of a PM action \\
\hline$C_{r}$ & Cost to search and repair the assignable cause \\
\hline$C_{v}$ & Variable cost of sampling \\
\hline$E\left(C_{f a}\right)$ & Expected false alarm cost per production cycle \\
\hline$E\left(C_{O P}\right)$ & Expected operation cost per production cycle \\
\hline$E\left(C_{O p_{i n}}\right)$ & Expected operation cost when the process is in the in-control state \\
\hline$E\left(C_{O p_{\text {out }}}\right)$ & Expected operation cost when the process is in the out-of-control state \\
\hline$E\left(C_{r}\right)$ & Expected search and repair cost per production cycle \\
\hline$E\left(C_{s}\right)$ & Expected sampling cost per production cycle \\
\hline
\end{tabular}


Table 2. Notations (continued).

\begin{tabular}{cl}
\hline Notations & \multicolumn{1}{c}{ Description } \\
\hline Cost parameters: & \\
$E(H C)$ & Expected inventory holding cost per inventory cycle \\
$E(Q C)$ & Expected Preventive Maintenance $(\mathrm{PM})$ cost per production cycle \\
$E T C$ & Expected quality cost per production cycle \\
$i r$ & Interest rate of cost \\
$S_{0}$ & Setup cost for each production cycle \\
& \\
parameters: & Expected length of the inventory period \\
$E\left(T_{I}\right)$ & Expected length of the production cycle that the process is in the in-control state \\
$E\left(T_{i n}\right)$ & Expected total length of the production cycle that the process is in the out-of-control state \\
$E\left(T_{\text {out }}\right)$ & Expected total length of the production cycle without considering PM times \\
$E\left(T_{P}\right), E T P$ & Expected total length of the production cycle including PM times \\
$E\left(T_{P+Z_{1}}\right)$ & Time to shift Probability Density Function (PDF) \\
$f(t)$ & Time to shift Cumulative Distribution Function (CDF) \\
$F(t)$ & Hazard rate function \\
$r(t)$ & Time at the end of the $j$ th interval \\
$t_{j}$ & Time at the beginning of the sth PM activity that is implemented with frequency $l$ \\
$t_{s l}$ & Virtual age of production system at time $t_{j}$ \\
$w_{j}$ & The expected time to perform a PM \\
$Z_{1}$ & A constant value for age reduction (rejuvenation) \\
$\gamma$ &
\end{tabular}

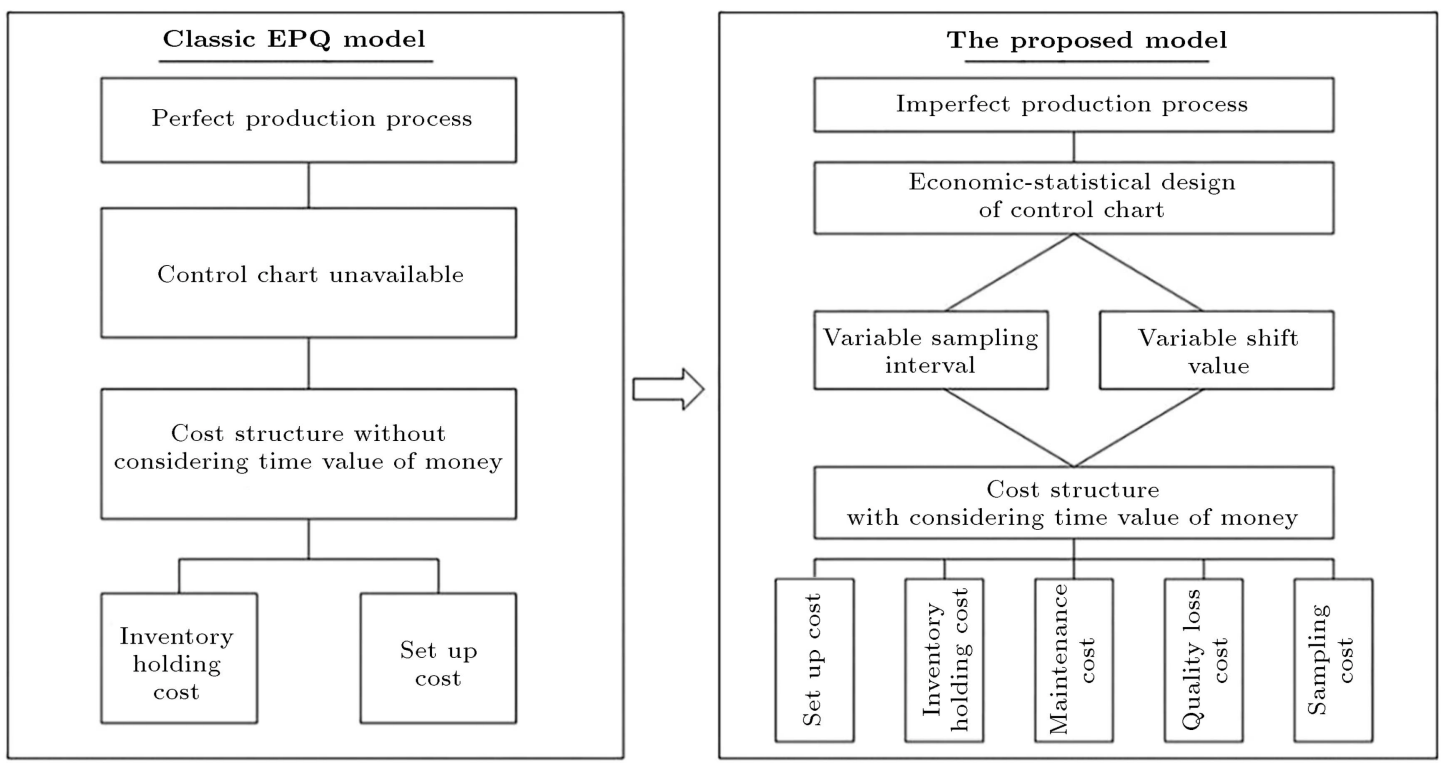

Figure 2. Graphical representation of cost structure.

$$
\begin{aligned}
& t_{j}=\sum_{i=1}^{j} h_{i}+\left(s \times Z_{1}\right) \\
& s= \begin{cases}\left\lfloor\frac{j}{l}\right\rfloor & \left\lfloor\frac{j}{l}\right\rfloor<\frac{j}{l} \\
\left\lfloor\frac{j}{l}\right\rfloor-1 & \left\lfloor\frac{j}{l}\right\rfloor=\frac{j}{l}\end{cases}
\end{aligned}
$$

6. The time spent for the sampling is ignorable because it is very small in comparison with the inventory cycle time.

7. At time $t_{m}$, the repair actions are implemented instead of the sampling to return the process to an as-good-as-new condition.

8. In this study similar to $\mathrm{Wu}$ et al. [31] and Celano 
et al. [32], it is assumed that the magnitude of shift size is positive and follows a Rayleigh distribution function.

9. The production cycle ends either with a true alarm or at time $t_{m}$.

10. The duration of sampling intervals is calculated such that the integrated failure rate is the same value for all intervals. In other words, $h_{j}(j=$ $1,2, \ldots, m)$ must satisfy Eq. (5):

$$
\int_{w_{j-1}}^{w_{j-1}+h_{j}} r(t) d t=\int_{0}^{h_{1}} r(t) d t .
$$

Thus, $h_{j}$ can be computed by Eq. (6):

$$
\begin{aligned}
h_{j} & =\left(w_{1}^{\nu}+w_{j-1}^{\nu}\right)^{\frac{1}{\nu}}-w_{j-1} \\
& =\left[h_{1}^{\nu}+\left((1-\gamma) \sum_{i=1}^{j-1} h_{i}\right)^{\nu}\right]^{\frac{1}{\nu}}-(1-\gamma) \sum_{i=1}^{j-1} h_{i} .
\end{aligned}
$$

Note that $h_{j}$ satisfies the following requirements:

$$
\begin{aligned}
& h_{1} \geq h_{2} \geq \ldots \geq h_{m}, \\
& \lim _{m \rightarrow \infty} \sum_{j=1}^{m} h_{j}=\infty .
\end{aligned}
$$

11. PM activities are synchronized with the sampling at times $t_{l}, t_{2 l}, t_{3 l}, \ldots$, where $l$ is a decision variable. At the end of these sampling intervals, the production system ceases at time units $Z_{1}$ to carry out PM activities.

$$
Z_{1_{j}}= \begin{cases}Z_{1} & \text { if } j=l, 2 l, 3 l, \ldots \\ 0 & \text { otherwise }\end{cases}
$$

12. The implementation of PM activity leads to the system rejuvenation. The relationship between PM activities and age reduction is defined in Eq. (10), where $w_{j}$ is the virtual age of production system at time $t_{j}$ and $\gamma$ is the constant value for age reduction:

$$
\begin{aligned}
& w_{0}=0 \\
& w_{j}=w_{j-1}+(1-\gamma) h_{j} \quad j=1,2, \ldots, m .
\end{aligned}
$$

13. The manufacturer pays the inventory holding cost at the end of the cycle.

\section{Model description}

This section explains the proposed mathematical model according to the problem definition and the assumptions. For this purpose, the next subsection calculates the production cycle length; then, Section 3.2 expresses the concepts of NPV. Afterwards, Section 3.3 indicates the cost structure based on NPV and formulates the sampling cost, the quality loss cost, the maintenance cost, the inventory holding cost, and the setup cost. Finally, the last subsection represents clearly the objective function and constraints.

\subsection{Production cycle time}

According to Eq. (11), the expected production cycle length $E\left(T_{P}\right)$ includes the production time in both the in-control and out-of-control states.

$$
\begin{aligned}
E\left(T_{P}\right)= & \sum_{j=1}^{m} P_{j} \prod_{i=1}^{j-1}\left(1-P_{i}\right)\left(\sum_{s=1}^{j-1} h_{s}+\tau_{j}\right) \\
& +\sum_{j=1}^{m-1} P_{j} \prod_{i=1}^{j-1}\left(1-P_{i}\right)\left[(1-\beta)\left(h_{j}-\tau_{j}\right)\right. \\
& +\sum_{r=j+1}^{m-1} \beta^{r-j}(1-\beta)\left(\sum_{s=j+1}^{r} h_{s}+\left(h_{j}-\tau_{j}\right)\right) \\
& \left.+\beta^{m-j}\left(\sum_{s=j+1}^{m} h_{s}+\left(h_{j}-\tau_{j}\right)\right)\right] \\
& +P_{m} \prod_{i=1}^{m-1}\left(1-P_{i}\right)\left(h_{m}-\tau_{m}\right),
\end{aligned}
$$

where $P_{j+1}$ is the conditional probability of the process mean shifting to the out-of-control state at $\left(t_{j}, t_{j+1}\right)$ interval, while it was in the in-control state at the beginning of the $j$ th sampling interval:

$$
P_{j+1}=\frac{F\left(w_{j}+h_{j+1}\right)-F\left(w_{j}\right)}{1-F\left(w_{j}\right)} .
$$

Finally, the expected inventory cycle length is given by:

$$
E\left(T_{I}\right)=\frac{P}{D} \times E\left(T_{P}\right) .
$$

At the end of this section, to clarify the abovementioned descriptions, Figure 3 depicts graphically a given inventory cycle.

\subsection{Time value of money}

To make the mathematical model more adaptable to the real cost imposed on the manufacturer, this study considers the time value of money in calculating the system cost. According to the state-of-the-art in the literature such as El-Kassar et al. [33] and Disney et al. [22], NPV is selected as a method to calculate the total cost of the manufacturing system, considering the time value of money. With respect to the continuous interest rate, the Present Value (PV) of single future cash flow $(F)$ at time $t$ is given by:

$$
P V=F \times e^{-(i r) \times t} \text {. }
$$

For a continuous cash flow per time unit repre- 


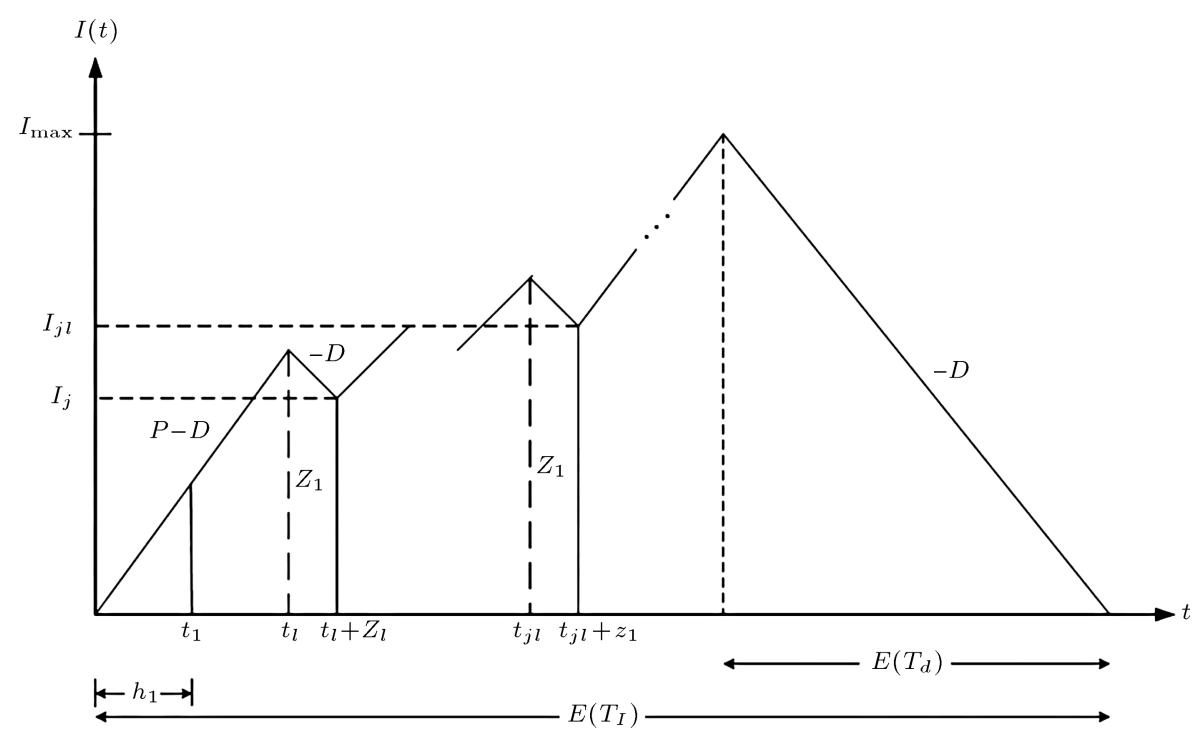

Figure 3. Graphical representation of the inventory cycle.

sented by a continuous function $f(t)$ and extended over a period $[0, t]$, the present value is equal to Eq. (15):

$$
P V=\int_{0}^{t} f(t) e^{-i r \cdot t} d t
$$

In the next section, the system costs are calculated considering the time value of money with a continuous interest rate.

\subsection{Cost model structure}

This section aims to calculate the costs of the manufacturing system consisting of the sampling cost, quality control cost, maintenance cost, inventory holding cost, and setup cost considering the NPV factor.

\subsubsection{Sampling cost}

To calculate the expected sampling cost per production cycle, the probability of sampling must be multiplied by the sum of the fixed and variable costs of sampling. It is obvious that, in addition to the sampling in the in-control state, the sample may be taken in the outof-control state due to type-II error. Therefore, both states are considered in computing this cost, and the expected sampling cost without considering the time value of money is as follows:

$$
\begin{aligned}
E\left(C_{s}\right)= & \left(C_{f}+n C_{v}\right)\left[1+\sum_{j=2}^{m-2} j \sum_{s=1}^{j} P_{s} \beta^{j-s}(1-\beta)\right. \\
& \prod_{i=1}^{s-1}\left(1-P_{i}\right)+(m-1)\left(\prod_{y=1}^{m-1}\left(1-P_{y}\right)\right. \\
& \left.\left.+\sum_{j=1}^{m-1} P_{j} \beta^{(m-1)-j} \prod_{i=1}^{j-1}\left(1-P_{i}\right)\right)\right] .
\end{aligned}
$$

According to the above descriptions, Eq. (17) denotes the expected sampling cost considering the NPV factor:

$$
\begin{aligned}
E\left(C_{s}\right) & =\left(C_{f}+n C_{v}\right)\left(e^{-i r . t_{1}}+\sum_{j=2}^{m-2} \sum_{k=1}^{j} e^{-i r . t_{k}}\right. \\
& \left(\sum_{s=1}^{j} P_{s} \beta^{j-s}(1-\beta) \prod_{i=1}^{s-1}\left(1-P_{i}\right)\right)+\sum_{y=1}^{m-1} e^{-i r . t_{y}} \\
\times & {\left.\left[\prod_{i=1}^{m-1}\left(1-P_{i}\right)+\sum_{j=1}^{m-1} P_{j} \beta^{m-1}-j \prod_{i=1}^{j-1}\left(1-P_{i}\right)\right]\right) }
\end{aligned}
$$

3.3.2. Quality control cost

The quality control cost consists of three parts: (1) operation cost, (2) cost of the false alarm, and (3) search and repair cost of the assignable cause. It is necessary to remember that the manufacturer incurs the operation cost in both of the in-control and out-ofcontrol states. However, this cost increases extremely when the process is in the out-of-control state due to an increase in the production rate of non-conforming items. Consequently, the operation cost includes the quality loss cost in both of in-control and out-ofcontrol states. Based on the model assumptions, since this model considers the NPV of operation cost, it is required to obtain the operation cost in three parts as follows: (1) the expected quality cost from the beginning of the process to the first PM activity, (2) the expected quality cost from the first PM to the last PM, and (3) the expected quality cost from the last PM to the end of the production cycle $\left(t_{m}\right)$. Thus, the expected operation cost in the in-control and outof-control states is formulated by Eqs. (18) and (19), respectively: 


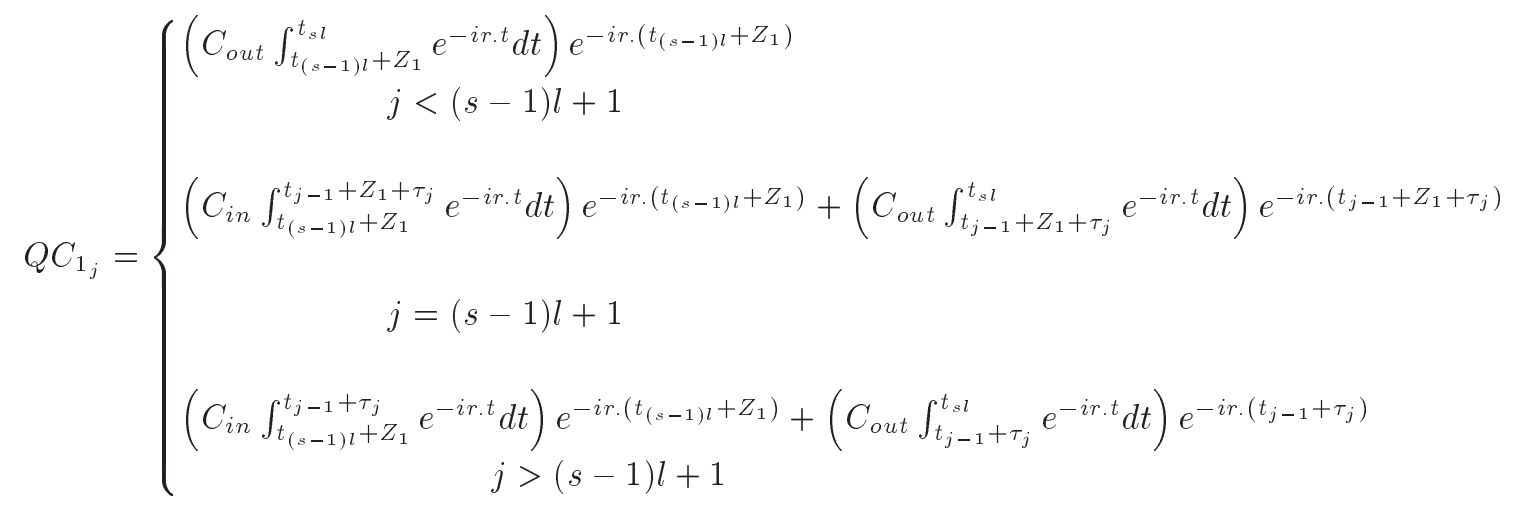

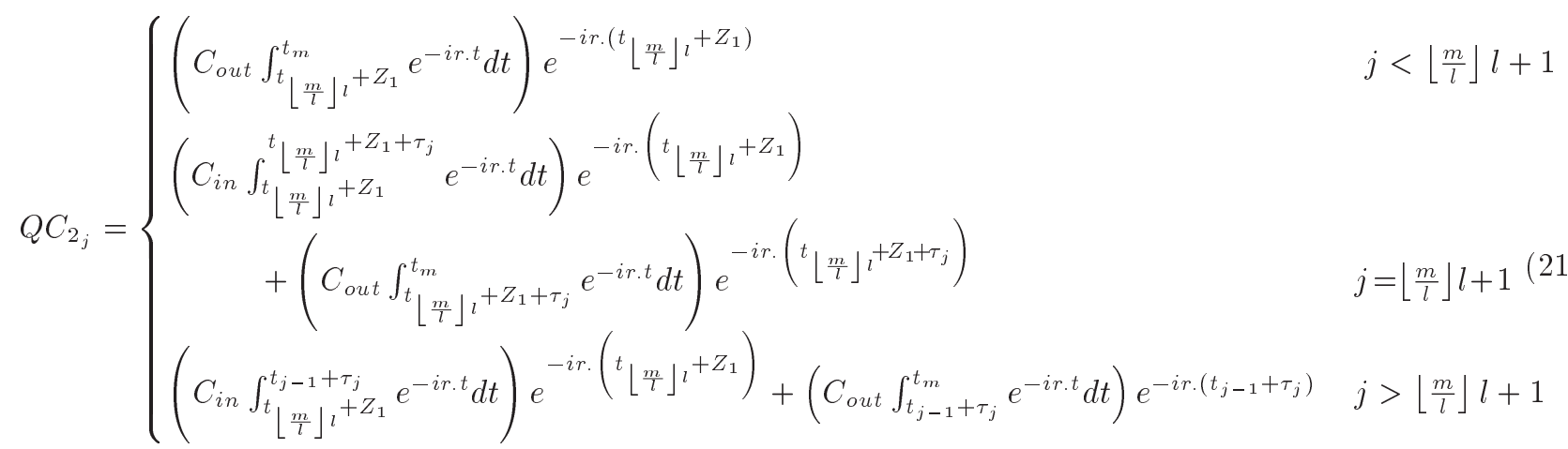

Box I

$$
\begin{aligned}
& E\left(C_{O P_{i n}}\right)=C_{i n} \prod_{i=1}^{l}\left(1-P_{i}\right) \int_{0}^{t_{l}} e^{-i r . t} d t \\
& +C_{i n} \sum_{j=1}^{\left\lfloor\frac{m}{l}\right\rfloor-1} \prod_{i=1}^{(j+1) l}\left(1-P_{i}\right) \\
& \left(\int_{t_{j l}+Z_{1}}^{t_{(j+1) l}} e^{-i r . t} d t\right) e^{-i r .\left(t_{j l}+Z_{1}\right)} \\
& +C_{i n} \prod_{i=1}^{m}\left(1-P_{i}\right)\left(\int_{t\left\lfloor\frac{m}{l}\right\rfloor l}^{t_{m}}+Z_{1}\right. \\
& \left.e^{-i r . t} d t\right) e^{-i r \cdot\left(t\left\lfloor\frac{m}{l}\right\rfloor l^{+Z_{1}}\right)} \text {, } \\
& E\left(C_{O P_{\text {out }}}\right)=\sum_{j=1}^{l} P_{j} \beta^{l-j+1} \prod_{i=1}^{j-1}\left(1-P_{i}\right) \\
& \left(\left(C_{i n} \int_{0}^{t_{j-1}+\tau_{j}} e^{-i r . t} d t\right)\right. \\
& \left.+\left(C_{\text {out }} \int_{t_{j-1}+\tau_{j}}^{t_{l}} e^{-i r \cdot t} d t\right) e^{-i r \cdot\left(t_{j-1}+\tau_{j}\right)}\right)
\end{aligned}
$$

$$
\begin{aligned}
& +\sum_{s=2}^{\left\lfloor\frac{m}{l}\right\rfloor} \sum_{j=1}^{s l} P_{j} \beta^{s l-j+1} \prod_{i=1}^{j-1}\left(1-P_{i}\right) \times Q C_{1_{j}} \\
& +\sum_{j=1}^{m} P_{j} \beta^{m-j} \prod_{i=1}^{j-1}\left(1-P_{i}\right) \times Q C_{2_{j}},
\end{aligned}
$$

where $Q C_{1}$ is the expected quality cost from the first $\mathrm{PM}$ to the last PM, and $Q C_{2}$ is the expected quality cost from the last PM to $t_{m}$ that can be obtained by Eqs. (20) and (21) as shown in Box I. Finally, the expected operation cost is calculated through Eq. (22):

$$
E\left(C_{O P}\right)=E\left(C_{O P_{i n}}\right)+E\left(C_{O P_{\text {out }}}\right) .
$$

Note that, in the mentioned formulas, the beginning time of the sth PM $\left(t_{s l}\right)$ is equal to that of Eq. (23). Moreover, if an assignable cause occurs during the $j$ th sampling interval $\left(t_{j-1}, t_{j}\right)$, the expected in-control duration within this interval $\left(\tau_{j}\right)$ is obtained through Eq. (24):

$$
\begin{aligned}
t_{s l} & =\sum_{j=1}^{s l} h_{j}+(s-1) Z_{1}, \\
\tau_{j} & =\int_{w_{j-1}}^{w_{j-1}+h_{j}}\left(t-w_{j-1}\right) \frac{f(t)}{\Delta F\left(t_{j}\right)} d t .
\end{aligned}
$$

Further, the quality cost per time unit when the 
process is in the out-of-control state $\left(C_{\text {out }}\right)$ is defined by Eq. (25):

$$
\begin{aligned}
C_{\text {out }}(\delta)= & \frac{A}{\Delta^{2}} \int_{-\infty}^{+\infty}\left(x-\mu_{0}\right)^{2} f(x) d x \\
& -\frac{A}{\Delta^{2}} \int_{L C L}^{U C L}\left(x-\mu_{0}\right)^{2} f(x) d x .
\end{aligned}
$$

On the other hand, this model assumes that the shift size follows a Rayleigh distribution with parameter $\mu_{\delta}$. According to Wu et al. [31], the Rayleigh distribution fits properly the random shift size when it behaves like a unimodal random variable. Hence, the PDF of $\delta$ is as follows:

$$
f_{\delta}(\delta)=\frac{\pi \delta}{2 \mu_{\delta}^{2}} e^{\frac{-\pi \delta^{2}}{4 \mu_{\delta}^{2}}}
$$

Consequently, the expected value of $C_{\text {out }}$ can be obtained by the following integral:

$$
E\left[C_{\text {out }}(\delta)\right]=\int_{0}^{\infty} C_{\text {out }}(\delta) f_{\delta}(\delta) d \delta .
$$

Moreover, the type-II error is calculated through Eq. (28); since it is dependent on the shift size, its expected value is as follows:

$$
\begin{aligned}
& \beta=P\left(L C L<\bar{X}<U C L \mid \mu_{0}+\delta_{\mu} \sigma_{0}\right) \\
& =\Phi\left(K-\delta_{\mu} \sqrt{n}\right)-\Phi\left(-K-\delta_{\mu} \sqrt{n}\right), \\
& E[\beta(\delta)]=\int_{0}^{\infty} \beta(\delta) f_{\delta}(\delta) d \delta .
\end{aligned}
$$

It is evident that, in all of the mentioned formulas, $E\left[C_{\text {out }}(\delta)\right]$ and $E[\beta(\delta)]$ are used instead of $C_{\text {out }}$ and $\beta$, respectively.

On the other hand, to compute the cost of the false alarm, the probability of issuing a false alarm at a given sampling interval is multiplied by the cost of each false alarm and NPV factor $\left(e^{-i r . t}\right)$. Therefore, the expected cost of the false alarm is obtained by:

$$
E\left(C_{f a}\right)=\alpha C_{f a} \sum_{j=1}^{m-1} e^{-i r . t_{j}} \prod_{i=1}^{j}\left(1-P_{i}\right) .
$$

In addition, to calculate the expected search and repair cost of the assignable causes $\left[E\left(C_{r}\right)\right]$, three elements are considered: the occurrence time of the assignable cause, the issuing time of the signal by the chart, and the repair cost that is implemented at the $m$ th sampling interval.

$$
\begin{aligned}
E\left(C_{r}\right)= & C_{r}\left(e^{-i r . t_{m}}\right. \\
& {\left[\prod_{i=1}^{m}\left(1-P_{i}\right)+P_{m} \prod_{i=1}^{m-1}\left(1-P_{i}\right)\right.}
\end{aligned}
$$

$$
\begin{aligned}
& \left.+\sum_{y=1}^{m-1} \beta^{m-y} P_{y} \prod_{i=1}^{y-1}\left(1-P_{i}\right)\right] \\
& +(1-\beta) \sum_{j=1}^{m-1} e^{-i r . t_{j}} \sum_{y=1}^{j} P_{y} \beta^{j-y} \\
& \left.\prod_{i=1}^{y-1}\left(1-P_{i}\right)\right) .
\end{aligned}
$$

Eventually, the expected quality cost is defined by:

$$
E(Q C)=E\left(C_{O P}\right)+E\left(C_{f a}\right)+E\left(C_{r}\right) .
$$

\subsubsection{Maintenance cost}

In this study, the PM activity is implemented under two conditions: (1) the process operates in the incontrol state and (2) the production system shifts to the out-of-control state and, thus, the type-II error occurs. Therefore, to obtain the expected maintenance cost, the occurrence probability of the two mentioned conditions is multiplied by the number of PM activities in each condition and the cost of PM activities. Consequently, the expected PM cost considering NPV is defined by Eq. (33) as shown in Box II.

\subsubsection{Inventory holding cost}

According to the classical EPQ model, the expected inventory holding cost is given by:

$$
E(H C)=C_{i} \times \int_{0}^{E\left(T_{I}\right)} I(t) d t=C_{i} \times E(A),
$$

where $I(t)$ is the function of the inventory level, and $E(A)$ denotes the expected area under $I(t)$.

Since this paper supposes that the inventory holding cost is imposed on the manufacturer at the end of each cycle, the NPV of $E(H C)$ is:

$$
E(H C)=C_{i} E(A) e^{-i r E\left(T_{I}\right)} .
$$

In the above formulas, $E(A)$ is computed according to Ben-Daya and Makhdoum [18] and Ben-Daya [2] as below:

$$
\begin{aligned}
E(A)= & \sum_{j=1}^{m} U_{j} \prod_{i=1}^{j-1}\left(1-P_{i}\right) \\
& +(1-\beta) \sum_{j=1}^{m-1} B_{j} P_{j} \prod_{i=1}^{j-1}\left(1-P_{i}\right) \\
& +\beta \sum_{j=1}^{m-1} P_{j} \prod_{i=1}^{j-1}\left(1-P_{i}\right) \\
& \times\left(\sum_{i=j+1}^{m} \beta^{i-j-1} U_{i}+\beta^{m-j} B_{m}\right)
\end{aligned}
$$




$$
\begin{aligned}
E(P M)= & C_{P M}\left(\sum _ { s = 1 } ^ { \lfloor \frac { m } { l } \rfloor - 1 } ( \sum _ { k = 1 } ^ { s } e ^ { - i r \cdot t _ { k l } } ) \left[\prod_{i=1}^{s l}\left(1-P_{i}\right) \sum_{r=s l+1}^{(s+1) l-1} P_{r} \prod_{y=s l+1}^{r-1}\left(1-P_{y}\right) \sum_{j=r}^{(s+1) l-1} \beta^{j-r}(1-\beta)\right.\right. \\
& \left.+\sum_{f=1}^{s l} P_{s l-f+1} \times \beta^{f} \prod_{i=1}^{s l-f}\left(1-P_{i}\right) \sum_{z=s l+1}^{(s+1) l-1} \beta^{z-(s l+1)}(1-\beta)\right]+\left(\sum_{s=1}^{\left\lfloor\frac{m}{l}\right\rfloor} e^{-i r . t_{s l}}\right)\left(\prod_{i=1}^{\left\lfloor\frac{m}{l}\right\rfloor}\left(1-P_{i}\right)\right. \\
& \left.\left.+\sum_{j=1}^{\left\lfloor\frac{m}{l}\right\rfloor l} P_{\left\lfloor\frac{m}{l}\right\rfloor l-j+1} \beta^{j} \prod_{i=1}^{\left\lfloor\frac{m}{l}\right\rfloor l-j}\left(1-P_{i}\right)\right)\right)
\end{aligned}
$$

Box II

$$
+B_{m} \prod_{i=1}^{m-1}\left(1-P_{i}\right)
$$

where $B_{j}$ is the area under $I(t)$ after $t_{j}$ if the process is out of control at time $t_{j}$. The values of $U_{j}$ and $B_{j}$ are defined as follows:

$$
\begin{aligned}
& U_{j}=\left\{\begin{array}{c}
\left(2 I_{j-1}+(P-D) h_{j}\right) \frac{h_{j}}{2}+\frac{\left(I_{j-1}+(P-D) h_{j}\right)^{2}}{2 D} \\
I_{j}=0, \quad j=1,2, \ldots, m \\
\left(2 I_{j-1}+(P-D) h_{j}\right) \frac{h_{j}}{2}+\left(I_{j-1}+(P-D) h_{j}(37)\right. \\
\left.+I_{j}\right) \frac{Z_{1_{j}}}{2} \\
I_{j}>0, \quad j=1,2, \ldots, m
\end{array}\right. \\
& B_{j}=\frac{I_{j}^{2}}{2 D} \quad j=1,2, \ldots, m .
\end{aligned}
$$

In the above equations, $I_{j}$ is the inventory level at time $t_{j}+Z_{1_{j}}$ for $j=1,2, \ldots, m-1$, and $I_{m}$ is the inventory level at time $t_{m}$. Eqs. (38) and (39) show $I_{j}$ and $I_{m}$, respectively:

$$
\begin{aligned}
& I_{j}=I_{j-1}+(P-D) h_{j}-D Z_{1_{j}}, \\
& I_{m}=I_{m-1}+(P-D) h_{m} .
\end{aligned}
$$

\subsection{Mathematical model}

In this section, with respect to the explained costs in the previous section, the mathematical model consisting of the objective function and constraints is as follows:

$$
\begin{aligned}
& \operatorname{Min} Z: E T C= \\
& \frac{S_{0}+E(H C)+E(P M)+E(Q C)+E\left(C_{s}\right)}{E\left(T_{I}\right)},
\end{aligned}
$$

subject to:

$$
\begin{aligned}
& A R L_{0}>A R L_{l}, \\
& A R L_{1}<A R L_{u}, \\
& n_{l} \leq n \leq n_{u} ; \quad h_{l} \leq h_{1} \leq h_{u}, \\
& m \geq m_{l}, \\
& h_{j}, k>0 ; \quad n, m, l \in N^{+} ; \quad l<m .
\end{aligned}
$$

The Expected Total Cost (ETC) per time unit includes the summation of the setup cost, inventory holding cost, maintenance cost, quality control cost, and sampling cost. Moreover, the model constraints are as follows:

1. According to Eq. (41a), to reduce the number of false alarms without affecting the efficiency of control chart, $A R L_{0}$ must be larger than a predetermined lower bound $\left(A R L_{l}\right)$.

2. The control chart should issue a signal as soon as possible after the occurrence of an assignable cause to decrease the type-II error. Hence, Eq. (41b) guarantees that $A R L_{1}=\frac{1}{1-\beta}$ is less than the predetermined value of $A R L_{u}$.

3. Typically, in the real industrial environments due to economic reasons, the sample size and the length of the first sampling interval must be limited between two specific lower and upper limits, as given in Eq. (41c).

4. To assure the continuity of the process, the number of sampling intervals in a perfect cycle must be larger than the predetermined value of $m_{l}$; Eq. (41d) shows this constraint mathematically.

5. Eq. (41e) ensures that the sample size, the number of sampling intervals, and the frequency of PM actions are positive integer values, while the values 
of $h_{j}$ and $k$ are the real numbers. In addition, it ensures that the frequency of PM actions is less than $m$.

\section{Solution approach}

Since meta-heuristic algorithms can obtain nearoptimal results in an appropriate amount of time for the complex problems, academic researchers usually employ these algorithms to solve the complicated models. In the proposed mathematical model, some of the decision variables are in the CDF of a standard normal distribution or in the limits of an integral in the objective function. Moreover, the solution space is non-convex due to the simultaneous existence of both continuous and discrete decision variables in the mathematical model. According to the mentioned explanations, the application of the exact methods for solving mathematical programming (Eq. (40)) is very difficult. Consequently, this paper applies a metaheuristic algorithm for solving the proposed model similar to many papers in the literature. For instance, Faraz and Saniga [34] designed a $T^{2}$ control chart with double warning lines economically and statistically by Genetic Algorithm (GA). Bashiri et al. [35] presented an economic statistical design of $X$-bar chart using Multi-Objective Genetic Algorithm (MOGA). Chih et al. [36] utilized Particle Swarm Optimization (PSO) for the economic statistical design of $X$-bar control chart.

This study employs the PSO algorithm because of its acceptable efficiency in optimizing non-linear models, unique searching mechanism, and simple concepts [37]. The PSO is one of the most popular meta-heuristic algorithms that has widely been utilized recently by some authors such as Niaki et al. [38] and Hajinejad et al. [39]. In the following section, the PSO algorithm is explained in detail.

\subsection{Particle Swarm Optimization (PSO)}

PSO is a population-based algorithm that was first proposed based on the social behavior of birds, bees, and fishes. This algorithm employs the sharing of information among the population members called particles. Each particle in the PSO consists of two characteristics: (1) fitness value and (2) velocity vector. The first one denotes the valuation of the solution suitability, while the second one specifies the particle direction movement.

The PSO algorithm incorporates local and global searches to obtain high search efficiency. It is initialized with a swarm of particles with random positions and velocities. Then, the algorithm searches for the optimal solution by updating particle characteristics according to the force of inertia and the two "best" values called personal best (pbest) and global best (gbest). pbest is the best value experienced by the $i$ th particle, and gbest is the best solution observed so far. In other words, the velocity and position of the particle in each iteration are updated that affect three factors: (1) the current velocity, (2) the personal best, and (3) the global best. To clarify the PSO algorithm, Table 3 introduces the parameters of this algorithm briefly.

Many papers consider the amount of $\left(c_{1}+c_{2}\right)$ equal to 4 based on Kennedy et al. [40]. Moreover, the initial value of $w$ is selected at the interval $[0,1]$ and decreases to $w \cdot w_{d a m p}$ in each iteration to increase the intensification of the algorithm, where $w_{\text {damp }}$ is a fixed factor less than 1 . Figure 4 illustrates the computational procedure of the PSO algorithm in detail.

\subsection{Particle representation}

One of the major factors in applying the PSO algorithm is the particle representation. This study considers a five-dimensional vector of decision variables according to Eq. (42) as the solution representation:

$$
x_{i}^{t}=\left[h_{1}, k, n, m, l\right] .
$$

It is remembered that the length of the first sampling interval $\left(h_{1}\right)$ and the control limit coefficient of the $X$-bar control chart $(k)$ are two real numbers,

Table 3. Particle Swarm Optimization (PSO) parameters.

\begin{tabular}{cl}
\hline PSO parameters & \multicolumn{1}{c}{ Description } \\
\hline$N$ & Number of particles in the swarm \\
$x_{i}^{t}$ & Position of the $i$ th particle in iteration $t$ \\
$v_{i}^{t}$ & Velocity of the $i$ th particle in iteration $t$ \\
$p b e s t_{i}^{t-1}$ & Personal best of the $i$ th particle in iteration $t$ \\
$g b e s t^{t}$ & Best solution founded until iteration $t$ \\
$b_{l o}$ & Lower bound of the decision variables (search space) \\
$b_{u p}$ & Upper bound of the decision variables (search space) \\
$c_{1}$ & Recognition learning factor \\
$c_{2}$ & Social learning factor \\
$w$ & Inertia weight \\
\hline
\end{tabular}




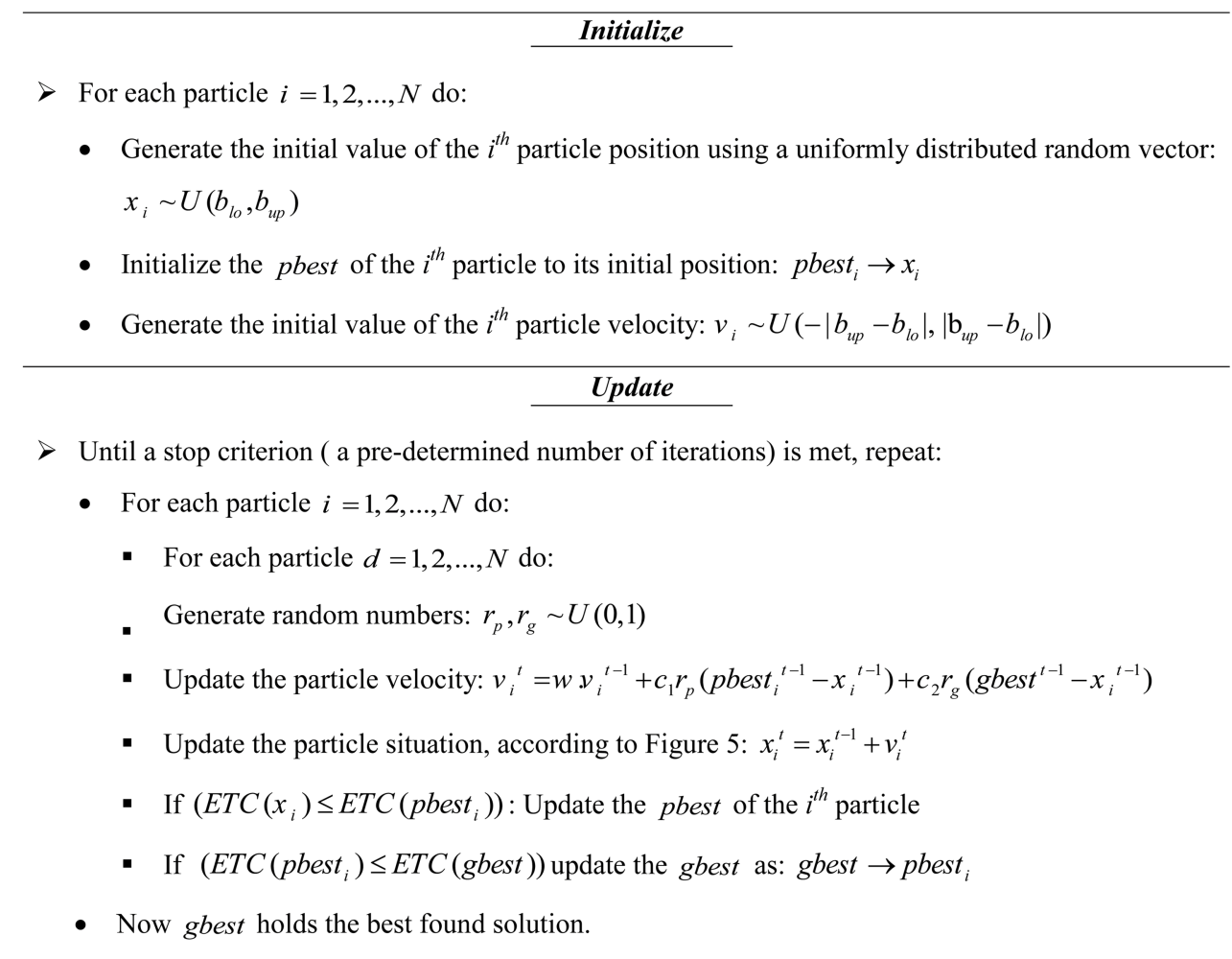

Figure 4. Computational procedure of the Particle Swarm Optimization (PSO) algorithm.

while the sample size $(n)$, the number of sampling intervals $(m)$, and frequency of PM activity $(l)$ are intrinsically positive integer numbers.

As mentioned earlier, the initial values of $h_{1}$ and $k$ are generated randomly from a uniform distribution between their corresponding lower and upper limits. Moreover, to generate the initial values of the other variables, firstly, random values from a uniform distribution at the interval $[0,1]$ are selected. Then, $n$, $m$, and $l$ are calculated by Eqs. (43)-(45), respectively. In the subsequent iterations the particle velocity and particle position are updated according to Figure 5, and the algorithm stops when the iteration number reaches a predetermined value.

$$
\begin{aligned}
& n=\min \left(n_{\min }+\left\lfloor\left(n_{\max }-n_{\min }+1\right) \times R_{1}\right\rfloor, n_{\max }\right), \\
& m=\min \left(m_{\min }+\left\lfloor\left(m_{\max }-m_{\min }+1\right) \times R_{2}\right\rfloor, m_{\max }\right), \\
& l=\min \left(l_{\min }+\left\lfloor\left(l_{\max }-l_{\min }+1\right) \times R_{3}\right\rfloor, l_{\max }\right),
\end{aligned}
$$

where $n_{\min }, n_{\max }, m_{\min }, m_{\max }, l_{\min }$, and $l_{\max }$ are the lower and upper limits of $n, m$, and $l$, respectively. Moreover, $R_{1}, R_{2}$, and $R_{3}$ are three random numbers from a uniform distribution at the interval $[0,1]$.

\section{Experimental results}

As already mentioned, the aim of the proposed math-

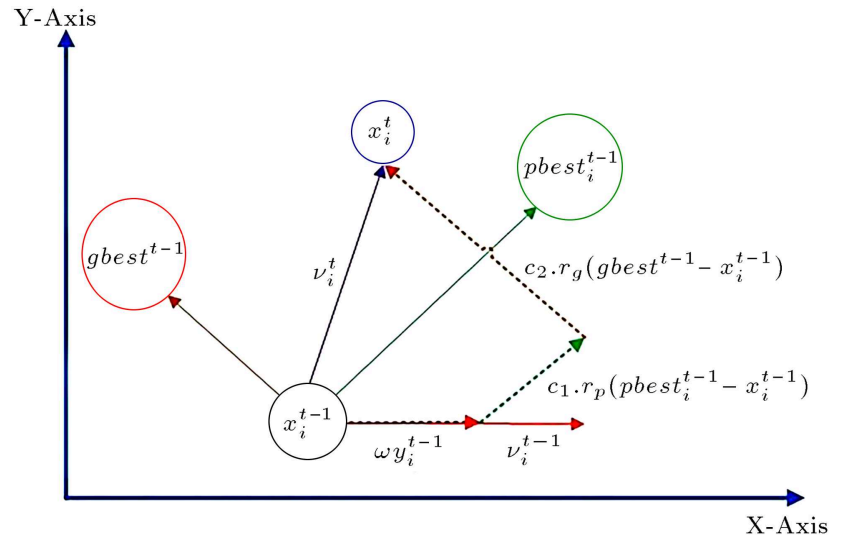

Figure 5. Particle Swarm Optimization (PSO) position and velocity update [41].

ematical programming is to minimize the ETC per manufacturing cycle subject to economic and statistical constraints. In the following section, to demonstrate the applicability of the suggested model, a numerical example is defined based on a case study extended from Lee and Rahim [42]. Section 5.2 represents a comparative study to compare the model performance with that of the traditional models. In Section 5.3, a sensitivity analysis is implemented on four parameters of the model: (1) the shape parameter of the Weibull distribution $(\nu),(2)$ the scale parameter of the Weibull distribution $(\lambda)(3)$ the interest rate $(i r)$, and (4) the constant value of the age reduction $(\gamma)$. 


\subsection{Numerical example}

This section introduces an industrial example derived from Lee and Rahim [42] to indicate the applicability of the proposed model. This example investigates a wood cutting process, in which the failure of woodchoppers is generally associated with the equipment age. The woodchoppers usually break down during the manufacturing process when the poor-quality lumber has rocks, nails, or plastics embedded in the trunk. If no prior investigation has been done, it is likely that the teeth of the woodchoppers deteriorate earlier than the expected time and, hence, the process fails completely. In this situation, the added costs are imposed on the manufacturing costs because of the machine downtime and replacement of the cutting blades.

Suppose that the system failure mechanism is approximately followed by the Weibull distribution with the scale parameter $\lambda=0.2$ and the shape parameter $\nu=5$. An $X$-bar chart is employed for monitoring the quality characteristic, in which samples are taken from the process with the fixed and variable sampling costs of about $\$ 2$ and $\$ 0.1$, respectively. The expected time to perform a PM is $Z_{1}=0.1$ time units. It is also estimated that the setup cost $\left(S_{0}\right)$, the inventory holding cost per unit per time unit $\left(C_{i}\right)$, and cost of each false alarm $\left(C_{f a}\right)$ are about $\$ 2000, \$ 0.1$, and $\$ 400$. The values of the other main parameters related to the manufacturing system are recorded briefly in Table 4 .

Moreover, to make the presented model more adaptable to the real manufacturing environments, the sample sizes and the sampling intervals should be limited. To be specific, some industrial applications and priorities require exerting limitations on the decision variables and the selection of the lower and upper bounds for them [43,44]. Furthermore, to ensure the best protection against false alarms, the value of ARL should be limited. Accordingly, the mathematical programming can be rewritten as follows:
$\operatorname{Min} Z: E T C$,

subject to:

$A R L_{0}>200$,

$A R L_{1}<3$

$1 \leq n \leq 10$

$0.3 \leq h_{1} \leq 0.9$

$m \geq 15$

$h_{j}, k>0 ; \quad n, m, l \in N^{+} ; \quad l<m$.

Finally, the mathematical model is solved by the PSO algorithm in MATLAB software. The number of iterations and population size of PSO are equal to 60 and 10, respectively, which are obtained through the trial-and-error process. The results of the numerical example are attained according to Table 5. The results indicate that the proposed model improves both economic and statistical measures, considerably.

\subsection{Comparative study}

To illustrate the efficiency of the presented model, it is compared to the several classical models based on three different aspects: (1) the comparison between models with fixed and variable sampling intervals, (2) the comparison between the ED and ESD models, and (3) the comparison based on the time value of money.

\subsubsection{Comparison between models with the fixed and variable sampling intervals}

In this section, to investigate the effect of using the variable sampling intervals on the manufacturer's cost, the suggested model is compared to a similar model with the fixed sampling intervals. As mentioned earlier, the length of sampling intervals in the proposed model

Table 4. Values of the parameters in the numerical example.

\begin{tabular}{ccccccccc}
\hline Parameter & $\boldsymbol{\mu}_{\mathbf{0}}$ & $\boldsymbol{\sigma}$ & $\boldsymbol{\delta}_{\boldsymbol{\mu}}$ & $\boldsymbol{P}$ & $\boldsymbol{D}$ & $\boldsymbol{A}$ & $\boldsymbol{\Delta}$ & $\boldsymbol{\gamma}$ \\
\hline Value & 2 & 2 & 2 & 2000 & 1500 & 7 & 0.1 & 0.1 \\
\hline Parameter & $\boldsymbol{S}_{\boldsymbol{0}}$ & $\boldsymbol{C}_{\boldsymbol{i}}$ & $\boldsymbol{C}_{\boldsymbol{r}}$ & $\boldsymbol{C}_{\boldsymbol{f}}$ & $\boldsymbol{C}_{\boldsymbol{v}}$ & $\boldsymbol{C}_{\boldsymbol{i n}}$ & $\boldsymbol{C}_{\boldsymbol{p} \boldsymbol{m}}$ & $\boldsymbol{i} \boldsymbol{r}$ \\
\hline Value & 2000 & 0.1 & 1000 & 2 & 0.1 & 600 & 500 & 0.1 \\
\hline
\end{tabular}

Table 5. The results of the numerical example.

\begin{tabular}{|c|c|c|c|c|c|c|c|c|c|}
\hline \multirow{3}{*}{$\begin{array}{c}\text { Title } \\
\text { Parameter }\end{array}$} & \multicolumn{9}{|c|}{ Optimal results } \\
\hline & \multicolumn{5}{|c|}{ Decision variables } & \multicolumn{2}{|c|}{ Statistical measures } & \multicolumn{2}{|c|}{ Economic measures } \\
\hline & $m^{*}$ & $n^{*}$ & $k^{*}$ & $h_{1}^{*}$ & $l^{*}$ & $A R L_{i n}$ & $A R L_{\text {out }}$ & $E T C^{*}$ & $E T P^{*}$ \\
\hline Value & 15 & 6 & 3.6212 & 0.9 & 8 & 3410.2 & 1.2796 & 102031.9274 & 16.869 \\
\hline
\end{tabular}




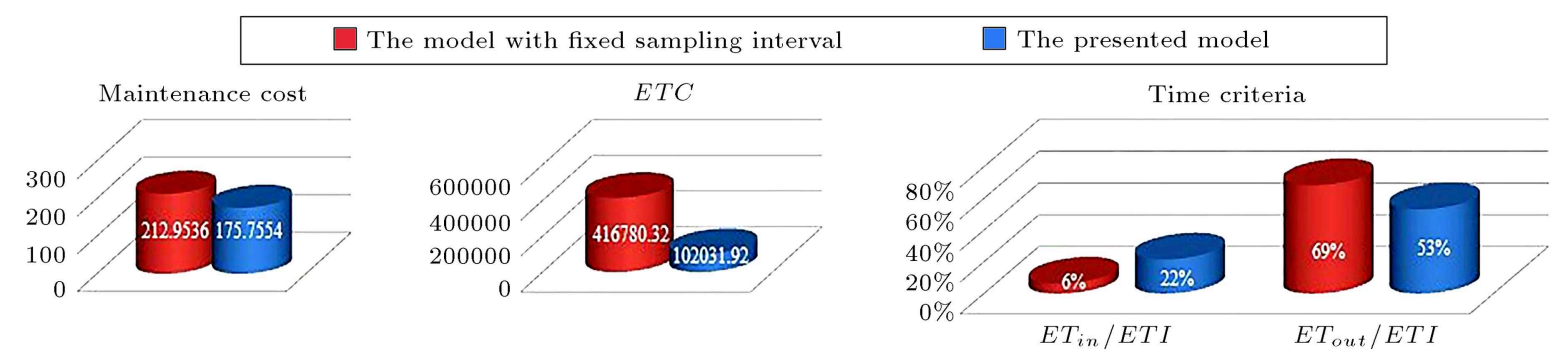

Figure 6. Graphical representations of the most important results of the comparative study.

Table 6. Comparison between the models with the fixed and variable sampling intervals .

\begin{tabular}{cccccccc}
\hline & \multicolumn{5}{c}{ Optimal results } \\
\cline { 2 - 7 } Model & $\boldsymbol{E} \boldsymbol{T C}$ & $\boldsymbol{E}(\boldsymbol{P} \boldsymbol{M})$ & $\boldsymbol{E}\left(\boldsymbol{C}_{\boldsymbol{O}_{\boldsymbol{i n}}}\right)$ & $\boldsymbol{E}\left(\boldsymbol{C}_{\boldsymbol{O}_{\text {out }}}\right)$ & $\boldsymbol{E} \boldsymbol{T I}$ & $\boldsymbol{E T}_{\text {in }}$ & $\boldsymbol{E T}_{\text {out }}$ \\
\hline Variable sampling intervals & 102031.92 & 175.7554 & 311.3442 & 19.7405 & 22.492 & 4.8816 & 11.9872 \\
Fixed sampling intervals & 416780.32 & 212.9536 & 22.1293 & 267.7903 & 38.6762 & 2.4937 & 26.5134 \\
\hline
\end{tabular}

Table 7. Comparisons between economic and economic-statistical designs.

\begin{tabular}{ccccc}
\hline & \multicolumn{4}{c}{ Optimal results } \\
\cline { 2 - 5 } Model & $\boldsymbol{A R L _ { \text { in } }}$ & $\boldsymbol{A R L _ { \text { out } }}$ & $\boldsymbol{E T P}^{*}$ & $\boldsymbol{E T C}^{*}$ \\
\hline Economic-statistical design & 3410.2 & 1.2796 & 16.869 & 102031.92 \\
Economic design & 1880.4 & 1.3093 & 16.871 & 101515.05 \\
Improvement (\%) & $81.36 \%$ & $2.27 \%$ & & \\
\hline
\end{tabular}

is calculated such that the integrated hazard rate at all intervals is the same. However, the sampling interval in the classical model is fixed regardless of the increasing failure rate over time. To illustrate the effect of a change in the sampling intervals on the cost and time criteria, the two mentioned models are compared together in the aforementioned industrial example. The obtained results are recorded in Table 6 .

According to Table 6 , when the sampling intervals are fixed, $E T_{i n} / E T I$ and $E T_{\text {out }} / E T I$ are equal 0.065 and 0.686 , respectively, while these ratios in the model with variable sampling intervals are 0.217 and 0.532 , respectively. Moreover, the values of $E\left(C_{O p_{\text {in }}}\right) / E\left(C_{O p_{\text {out }}}\right)$ in the models with fixed and variable sampling intervals are 0.083 and 15.772 , respectively. These results indicate that considering the fixed sampling interval leads to a remarkable increase in the cost and time of the out-of-control period. On the other hand, since the variable sampling interval prevents a decrease in the production system reliability, the maintenance cost of the proposed model is about $17.5 \%$ less than that of the model with the fixed sampling interval. Furthermore, the ETC of the manufacturing system increases dramatically when the sampling intervals are fixed. To clarify the above-mentioned results, the most important results of the comparative study are illustrated graphically in Figure 6.

\subsubsection{Comparison between ED and ESD models}

In this section, to confirm the model effectiveness, the ESD model and ED models are compared together in terms of economic and statistical criteria, i.e., ARLs and ETC. For this purpose, the proposed model is compared to a similar model without considering the statistical constraints. The results of the comparison between two ESD and ED models are demonstrated in Table 7.

As can be seen in Table 7, ETC of the economicstatistical model is approximately $0.51 \%$ more than that of the economic model, while the values of $A R L_{\text {in }}$ and $A R L_{\text {out }}$ improve dramatically by using ESD model. To consider more details, $A R L_{\text {in }}$ and $A R L_{\text {out }}$ in the ESD model are better than those of the ED model by about $81 \%$ and $2.27 \%$, respectively. To simplify the comparison between the two models, the economic and statistical criteria for both models are illustrated in Figure 7.

\subsubsection{Comparison based on the time value of money} As mentioned above, the value of money changes over time because of inflation and deflation. In this regard, 
Table 8. The effect of the time value of money in the suggested model.

\begin{tabular}{cccccc}
\hline & \multicolumn{4}{c}{ Optimal results } \\
\cline { 2 - 6 } Model & $\boldsymbol{E}(\boldsymbol{P} \boldsymbol{M})$ & $\boldsymbol{E}(\boldsymbol{Q C})$ & $\boldsymbol{E}(\boldsymbol{H C})$ & $\boldsymbol{E T P}$ & $\boldsymbol{E T C}$ \\
\hline With considering time value of money & 175.7554 & 1834.6 & 2290900 & 16.869 & 102031.92 \\
Without considering time value of money & 201.4433 & 32589 & 21718000 & 17.297 & 1231127.44 \\
\hline
\end{tabular}

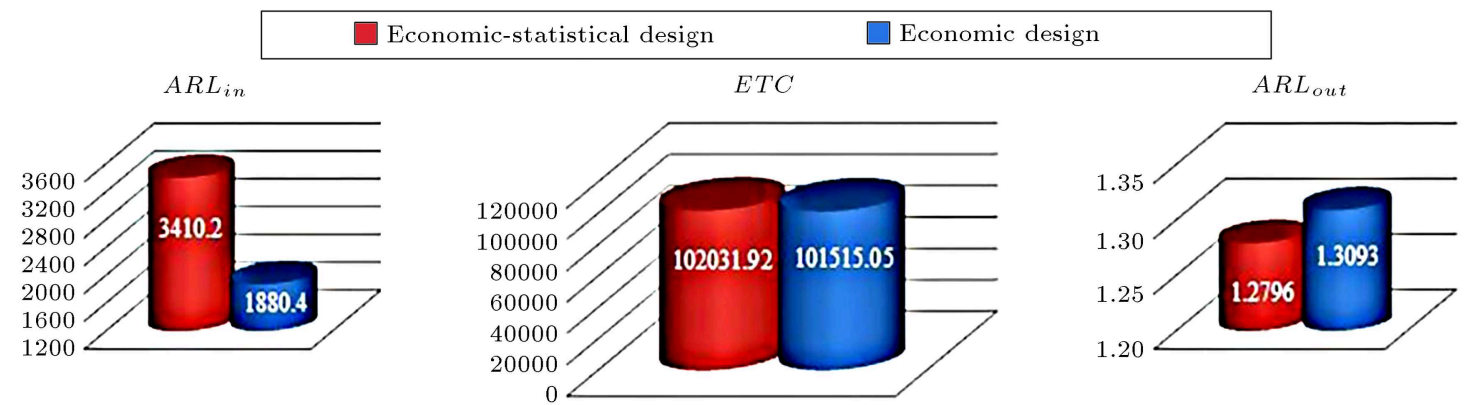

Figure 7. Results of the comparison between Economic Design (ED) and Economic-Statistical Design (ESD) models.

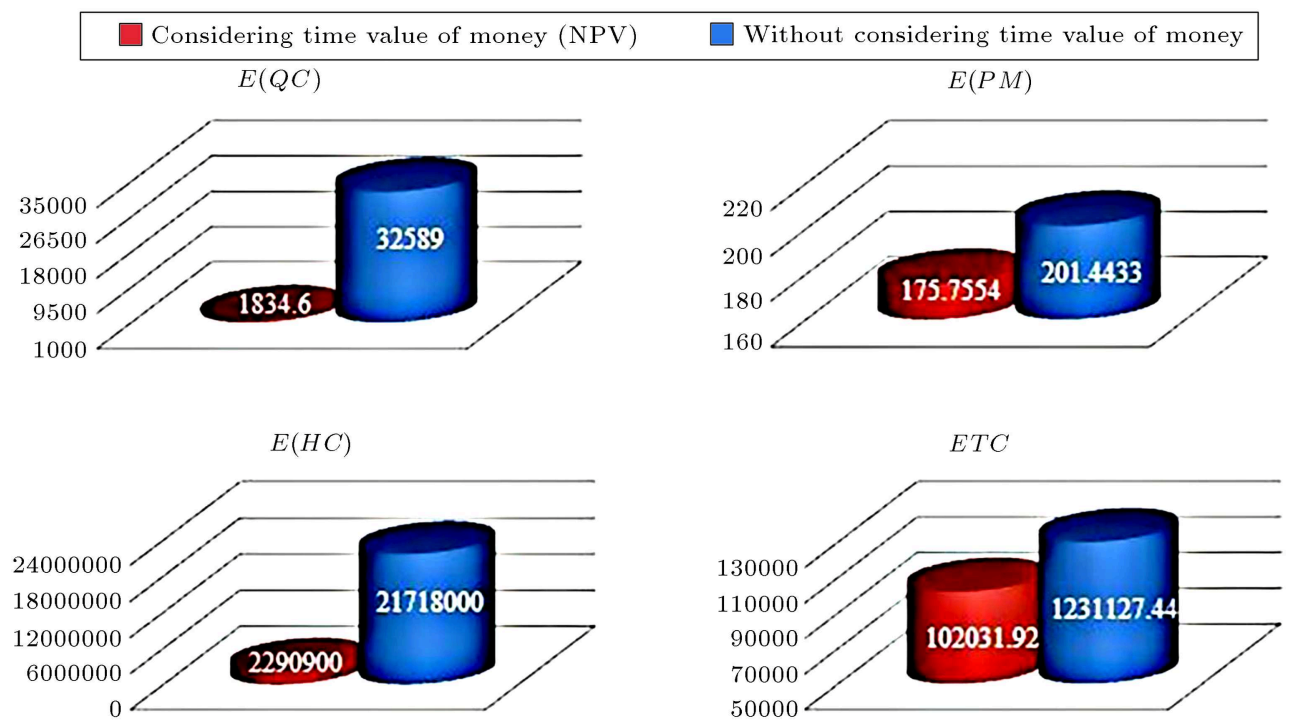

Figure 8. The comparison between the two models with and without considering the time value of money.

this section presents a comparative study between the presented model and a similar model without considering the time value of money. For this purpose, several cost parameters of the model are calculated with and without considering the time value of money. The results of the two models are represented in Table 8 .

As shown in Table 8, all types of costs in this study significantly change when considering the time value of money. Therefore, in countries with high inflation, the calculation of the $E T C$ without considering the time value of money is highly misleading because an increase in interest rate decreases the NPV of money. At the end of this section, the costs of both models are represented graphically in Figure 8.

\subsection{Sensitivity analysis}

According to the literature on production, this section analyzes the effect of the four major parameters on $E T C, E T P$, and the decision variables of the model. The considered parameters include the shape parameter of the Weibull distribution $(\nu)$, the scale parameter of the Weibull distribution $(\lambda)$, interest rate $(i r)$, and the age reduction parameter $(\gamma)$. The variations in the ETC, ETP, and decision variables are investigated by changing one of the parameters while keeping other parameters fixed. It must be noticed that the most important item in the sensitivity analysis is ETC that directly affects the profit of a company, and its sensitivity to the parameters can play an important role in making decisions by a manufacturer. The obtained 
Table 9. The results of sensitivity analysis.

\begin{tabular}{|c|c|c|c|c|c|c|c|c|}
\hline \multirow[b]{2}{*}{ Parameter } & \multirow[b]{2}{*}{ Value } & \multicolumn{5}{|c|}{ Decision variables } & \multirow[b]{2}{*}{$E T C$} & \multirow[b]{2}{*}{$E T P$} \\
\hline & & $m$ & $n$ & $k$ & $h_{1}$ & $l$ & & \\
\hline \multirow{3}{*}{$\nu$} & 3 & 15 & 7 & 3.4296 & 0.9 & 1 & 11364.7931 & 34.2758 \\
\hline & 5 & 15 & 6 & 3.6212 & 0.9 & 8 & 102031.9274 & 16.869 \\
\hline & 7 & 15 & 3 & 3.4641 & 0.9 & 8 & 224177.5128 & 11.7957 \\
\hline \multirow{3}{*}{$\lambda$} & 0.2 & 15 & 6 & 3.6212 & 0.9 & 8 & 102031.9274 & 16.869 \\
\hline & 1 & 15 & 3 & 3.7478 & 0.7333 & 2 & 127947.1505 & 14.2075 \\
\hline & 1.5 & 15 & 3 & 3.7503 & 0.6755 & 2 & 136760.9179 & 13.0976 \\
\hline \multirow{3}{*}{$i r$} & 0.1 & 15 & 6 & 3.6212 & 0.9 & 8 & 102031.9274 & 16.869 \\
\hline & 0.3 & 15 & 4 & 3.7706 & 0.9 & 8 & 1284.5895 & 13.2357 \\
\hline & 0.5 & 15 & 2 & 3.1493 & 0.9 & 15 & 147.2781 & 16.8474 \\
\hline \multirow{3}{*}{$\gamma$} & 0.1 & 15 & 6 & 3.6212 & 0.9 & 8 & 102031.9274 & 16.869 \\
\hline & 0.3 & 15 & 5 & 3.8018 & 0.9 & 8 & 100946.2008 & 16.9157 \\
\hline & 0.5 & 15 & 2 & 3 & 0.9 & 2 & 91188.784 & 19.3686 \\
\hline
\end{tabular}

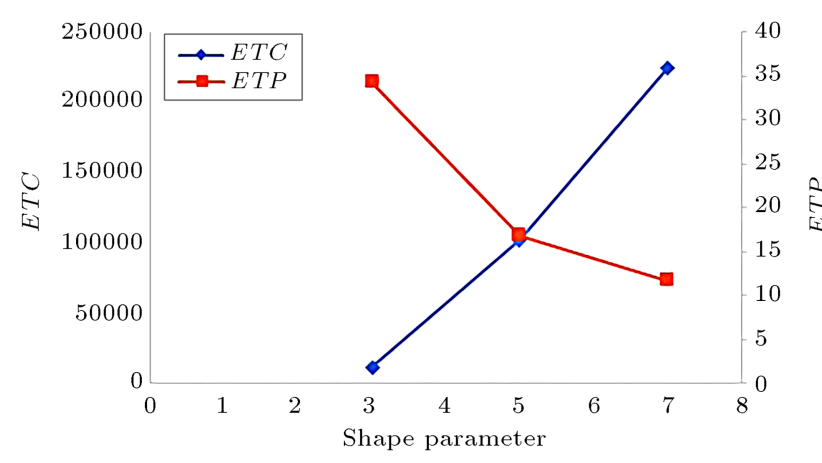

Figure 9. Effect of the shape parameter on $E T C^{*}$ and ETP*

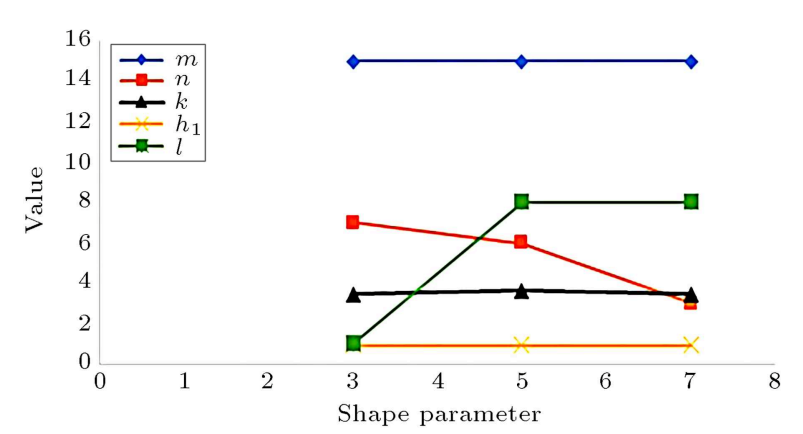

Figure 10. Effect of the shape parameter on the decision variables.

results of sensitivity analysis are reported in Table 9 and Figures 9-16.

\subsubsection{Effect of the shape parameter}

As shown in Figure 9, the value of ETC increases as the shape parameter of the Weibull distribution increments from 3 to 5 and from 5 to 7 , while the value of the expected production cycle length decreases in these situations. Figure 10 illustrates that as the

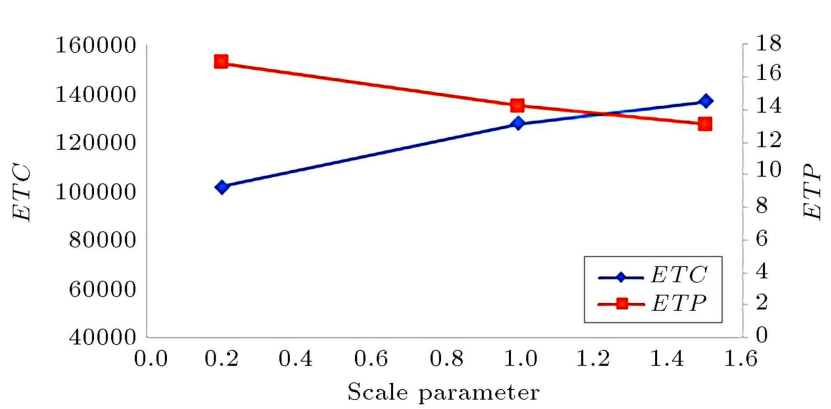

Figure 11. Effect of the scale parameter on $E T C^{*}$ and ETP ${ }^{*}$.

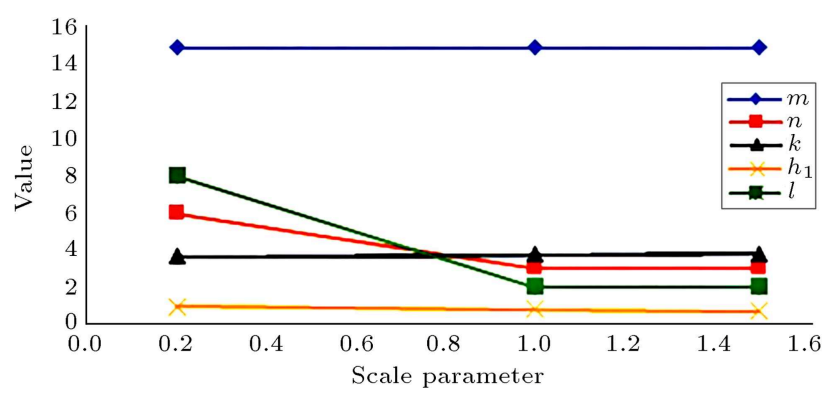

Figure 12. Effect of the scale parameter on the decision variables.

parameter $\nu$ increases from 3 to 7 , the optimal values of $h_{1}$ and $m$ remain fixed while $n$ decreases. On the other hand, a reduction in the control chart limit leads to an improvement in the type-II error probability. As a result, an increase in the shape parameter leads to the simultaneous reduction of sample size and control chart limit and enhances both of the economic and statistical criteria. Moreover, the design variable $k$ is insensitive to $\nu$, and the small variation in $k$ occurs only because of the random nature of PSO algorithm. 


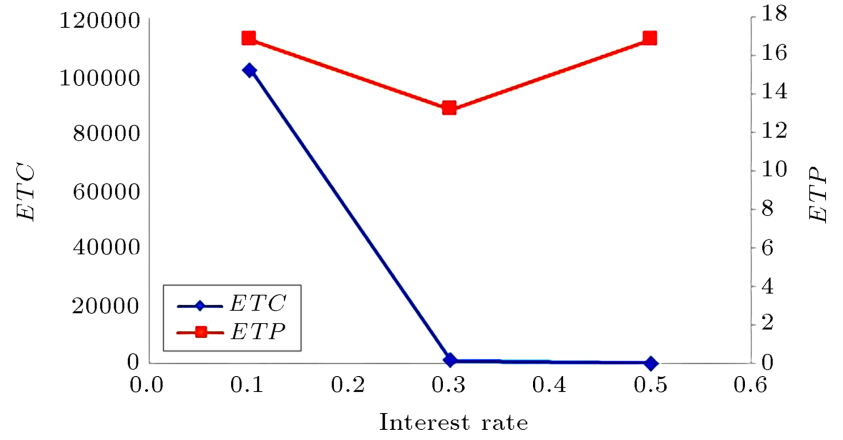

Figure 13. Effect of interest rate on $E T C^{*}$ and $E T P^{*}$.

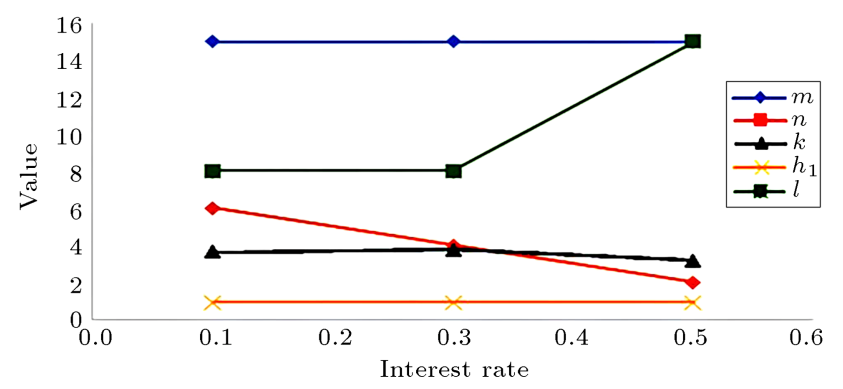

Figure 14. Effect of interest rate on the decision variables.

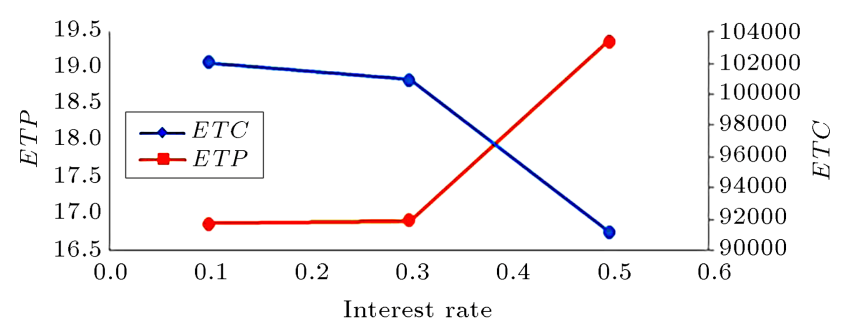

Figure 15. Effect of the age reduction parameter on $E T C^{*}$ and $E T P^{*}$.

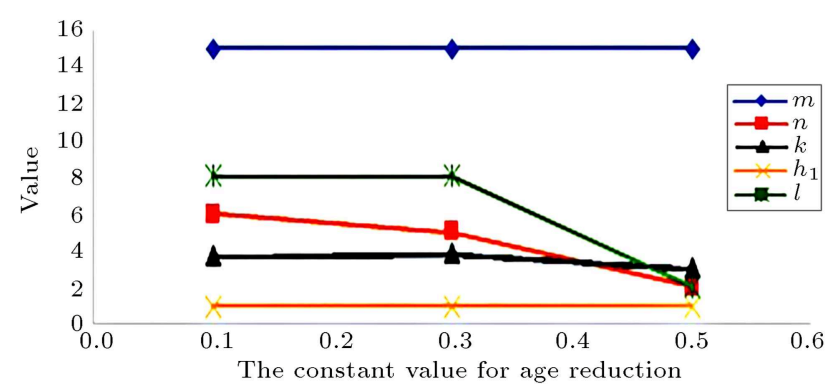

Figure 16. Effect of the age reduction parameter on the decision variable.

\subsubsection{Effect of the scale parameter}

According to Figure 11, as expected, when the scale parameter $(\lambda)$ increases, the occurrence probability of the assignable cause grows and ETP decreases, remarkably. For example, as $\lambda$ varies from 0.2 to 1.5, the value of $E T C$ increases to about 35000 units. It is obvious that an increase in the scale parameter leads to a higher risk of machine failure. Thus, it is expected that both of the expected maintenance cost and $E T C$ increase. Figure 12 illustrates that as the parameter $\lambda$ increases from 0.2 to 1.5 , the optimal value of $h_{1}$ decreases. In other words, with growing $\lambda$, the probability of the system failure increases and the sampling intervals decrease.

\subsubsection{Effects of the interest rate}

Figure 13 illustrates that the interest rate in contrast to the other parameters has an inverse relationship with the ETC. Since costs are calculated by the NPV method, the cost reduces dramatically with an increase in the interest rate. According to the expectations, as interest rate increases, the optimal value of $E T C$ decreases to approximately 102000 units.

\subsubsection{Effect of the age reduction parameter}

As expected, when the age reduction parameter increases, the total cost decreases; however, the production cycle length increases. It is reasonable that with an increase in the age reduction parameter, the probability of failure decreases and, consequently, the expected production cost reduces when the process is in the outof-control state. On the contrary, the production cycle length increases because of a reduction in the system age after implementing PM activities. Furthermore, as illustrated in Figure 16, incremental changes in the constant value of the age reduction cause $m$ and $h_{1}$ to remain unchanged and $k$ to vary mildly. In addition, as the age reduction parameter increases, $n$ and $l$ decrease due to a greater reduction in the virtual age system.

\section{Conclusion}

The major aim of this study is to bridge the gap between the simplified assumptions in the perfect manufacturing models and the real production situations. Accordingly, this research presented a joint model of production cycle length, maintenance, and the economic-statistical design of control chart that monitors an imperfect production process, considering stochastic shift size. In contrast to most of the studies in the literature, the model considered the time value of money for calculating the system costs. In addition, this paper employed a variable sampling interval such that the integrated hazard rate would be the same value over all the intervals. Finally, the model efficiency was analyzed by a comparative study based on an industrial example, and the sensitivity analysis was implemented to recognize the effects of the parameters on the objective function and decision variables. The results of the comparative study indicated that:

1. The cost and time of the out-of-control state in the proposed model were less than those of the model with the fixed sampling intervals; 
2. The model had a better performance in the statistical criteria in comparison with the economic design model;

3. Considering the time value of money led to a significant change in the real cost imposed on the manufacturer.

Furthermore, the results of performed sensitivity analysis demonstrated that the interest rate and the age reduction parameters had an inverse relationship with $E T C$, while an increase in the shape and the scale parameters of the Weibull distribution increased the model costs.

As for future research, the extension of the proposed model in two directions is suggested: first, developing a model that incorporates the ability to deal with a production system with parallel machines; second, simultaneous monitoring of the mean and variance of quality characteristics.

\section{References}

1. Ben-Daya, M. "The economic production lot-sizing problem with imperfect production processes and imperfect maintenance", International Journal of Production Economics, 76, pp. 257-264 (2002).

2. Ben-Daya, M. "Integrated production maintenance and quality model for imperfect processes", IIE Transactions, 31, pp. 491-501 (1999).

3. Cheng, L., Tsou, C.S., and Yang, D.Y. "Cost-service tradeoff analysis of reorder-point-lot-size inventory models", Journal of Manufacturing Systems, 37, pp. 217-226 (2015).

4. Zhou, X., Wu, C., Li, Y., and Xi, L. "A preventive maintenance model for leased equipment subject to internal degradation and external shock damage", Reliability Engineering \& System Safety, 154, pp. 1-7 (2016).

5. Costa, A.F. and Rahim, M.A. "Economic design of and R charts under Weibull shock models", Communications in Statistics-Theory and Methods, 42, pp. 39023925 (2013).

6. Gan, S., Zhang, Z., Zhou, Y., and Shi, J. "Joint optimization of maintenance, buffer, and spare parts for a production system", Applied Mathematical Modelling, 39, pp. 6032-6042 (2015).

7. Wen, D., Ershun, P., Ying, W., and Wenzhu, L. "An economic production quantity model for a deteriorating system integrated with predictive maintenance strategy", Journal of Intelligent Manufacturing, 27, pp. 1323-1333 (2016).

8. Rahim, M.A. and Ben-Daya, M. "Joint determination of production quantity, inspection schedule, and quality control for an imperfect process with deteriorating products", Journal of the Operational Research Society, 52, pp. 1370-1378 (2001).

9. Cheng, J.C. and Chou, C.Y. "A real-time inventory decision system using Western Electric run rules and ARMA control chart", Expert Systems with Applications, 35, pp. 755-761 (2008).

10. Xiang, Y. "Joint optimization of control chart and preventive maintenance policies: a discrete-time Markov chain approach", European Journal of Operational Research, 229, pp. 382-390 (2013).

11. Wu, J. and Makis, V. "Economic and economicstatistical design of a chi-square chart for CBM", European Journal of Operational Research, 188, pp. 516-529 (2008).

12. Makis, V. and Fung, J. "An EMQ model with inspections and random machine failures", Journal of the Operational Research Society, 49, pp. 66-76 (1998).

13. Jiang, Y., Chen, M., and Zhou, D. "Joint optimization of preventive maintenance and inventory policies for multi-unit systems subject to deteriorating spare part inventory", Journal of Manufacturing Systems, 35, pp. 191-205 (2015).

14. Salmasnia, A., Kaveie, M., and Namdar, M. "An integrated production and maintenance planning model under VP-T2 Hotelling chart", Computers \& Industrial Engineering, 118, pp. 89-103 (2018).

15. Bouslah, B., Gharbi, A., and Pellerin, R. "Integrated production, sampling quality control and maintenance of deteriorating production systems with AOQL constraint", Omega, 61, pp. 110-126 (2016).

16. Lin, Y.H., Chen, Y.C., and Wang, W.Y. "Optimal production model for imperfect process with imperfect maintenance, minimal repair and rework", International Journal of Systems Science: Operations \& Logistics, 4, pp. 229-240 (2017).

17. Beheshti Fakher, H., Nourelfath, M., and Gendreau, M. "A cost minimization model for joint production and maintenance planning under quality constraints", International Journal of Production Research, 55, pp. 2163-2176 (2017).

18. Ben-Daya, M. and Makhdoum, M. "Integrated production and quality model under various preventive maintenance policies", Journal of the Operational Research Society, 49, pp. 840-853 (1998).

19. Nourelfath, M., Nahas, N., and Ben-Daya, M. "Integrated preventive maintenance and production decisions for imperfect processes", Reliability Engineering and System Safety, 148, pp. 21-31 (2016).

20. Luciano, E. and Peccati, L. "Capital structure and inventory management: The temporary sale price problem", International Journal of Production Economics, 59, pp. 169-178 (1999). 
21. Van der Laan, E. "An NPV and AC analysis of a stochastic inventory system with joint manufacturing and remanufacturing", International Journal of Production Economics, 81, pp. 317-331 (2003).

22. Disney, S.M., Warburton, R.D., and Zhong, Q.C. "Net present value analysis of the economic production quantity", IMA Journal of Management Mathematics, 24(4), pp. 423-435 (2013).

23. Lin, R., Lin, J.S.J., Chen, K., and Julian, P.C. "Note on inventory model with net present value", Journal of Interdisciplinary Mathematics, 10, pp. 587-592 (2007).

24. Beullens, P. and Janssens, G.K. "Adapting inventory models for handling various payment structures using net present value equivalence analysis", International Journal of Production Economics, 157, pp. 190-200 (2014).

25. Duncan, A.J. "The economic design of $\mathrm{X}$ charts used to maintain current control of a process", Journal of the American Statistical Association, 51, pp. 228-242 (1956).

26. Saniga, E.M. "Economic statistical control-chart designs with an application to X and R charts", Technometrics, 31, pp. 313-320 (1989).

27. Nenes, G., Tasias, K.A., and Celano, G. "A general model for the economic-statistical design of adaptive control charts for processes subject to multiple assignable causes", International Journal of Production Research, 53, pp. 2146-2164 (2015).

28. Yin, H., Zhang, G., Zhu, H., Deng, Y., and He, F. "An integrated model of statistical process control and maintenance based on the delayed monitoring", Reliability Engineering and System Safety, 133, pp. 323-333 (2015).

29. Pan, E., Jin, Y., Wang, Sh., and Cang, T. "An integrated EPQ model based on a control chart for an imperfect production process", International Journal of Production Research, 50, pp. 6999-7011 (2012).

30. Salmasnia, A., Abdzadeh, B., and Namdar, M. "A joint design of production run length, maintenance policy and control chart with multiple assignable causes", Journal of Manufacturing Systems, 42, pp. 44-56 (2017).

31. Wu, Z., Shamsuzzaman, M., and Wang, Q. "The cost minimization and manpower deployment to SPC in a multistage manufacturing system", International Journal of Production Economics, 106, pp. 275-287 (2007).

32. Celano, G., De Magalhães, M.S., Costa, A.F., and Fichera, S. "A stochastic shift model for economically designed charts constrained by the process stage configuration", International Journal of Production Economics, 132, pp. 315-325 (2011).
33. El-Kassar, A.N., Salameh, M., and Bitar, M. "Effects of time value of money on the EPQ model with the imperfect quality items of raw material", Proceedings of Academy of Information and Management Sciences, New Orleans, 16(1), pp. 11-18 (2012).

34. Faraz, A. and Saniga, E. "Economic statistical design of a T2 control chart with double warning lines", Quality and Reliability Engineering International, 27, pp. 125-139 (2011).

35. Bashiri, M., Amiri, A., Doroudyan, M.H., and Asgari, A. "Multi-objective genetic algorithm for economic statistical design of control chart", Scientia Iranica, 20, pp. 909-918 (2013).

36. Chih, M., Yeh, L.L., and Li, F.C. "Particle swarm optimization for the economic and economic statistical designs of the control chart", Applied Soft Computing, 11, pp. 5053-5067 (2011).

37. Talbi, E.G., Metaheuristics from Design to Implementation, John Wiley \& Sons, Inc. (2009).

38. Niaki, S.T.A., Malaki, M., and Ershadi, M.J. "A particle swarm optimization approach on economic and economic-statistical designs of MEWMA control charts", Scientia Iranica, 18, pp. 1529-1536 (2011).

39. Hajinejad, D., Salmasi, N., and Mokhtari, R. "A fast hybrid particle swarm optimization algorithm for flow shop sequence dependent group scheduling problem", Scientia Iranica, 18, pp. 759-764 (2011).

40. Kennedy, J., Eberhart, R.C., and Shi, Y., Swarm Intelligence, San Francisco, Morgan Kaufmann Publishers (2001).

41. Perez, R.E. and Behdinan, K. "Particle swarm approach for structural design optimization", Computers \& Structures, 85, pp. 1579-1588 (2007).

42. Lee, B.H. and Rahim, M.A. "An integrated economic design model for quality control, replacement, and maintenance", Quality Engineering, 13, pp. 581-593 (2001).

43. Safaei, A.S, Kazemzadeh R.B., and Gan H.S. "Robust economic-statistical design of X-bar control chart", International Journal of Production Research, 53, pp. 4446-4458 (2015).

44. Seif, A., Faraz A., and Sadeghifar M. "Evaluation of the economic statistical design of the multivariate T2 control chart with multiple variable sampling intervals scheme: NSGA-II approach", Journal of Statistical Computation and Simulation, 85, pp. 24422455 (2015).

\section{Biographies}

Ali Salmasnia is currently an Assistant Professor at University of Qom, Qom, Iran. His research interests include quality engineering, reliability, applied multivariate statistics, and multi-criterion decisionmaking. He is the author or co-author of various papers published in the Journal of Manufacturing Systems, 
Applied Soft Computing, Neurocomputing, Applied Mathematical Modelling, etc.

Zahra Hajihosseini is an MS student at the Department of Industrial Engineering, Faculty of Technology and Engineering, University of Qom, Qom, Iran. Her current research interests include quality engineering and multi-criterion decision-making.

Mohammadreza Namdar received his MS degree in Industrial Engineering from the University of Qom,
Qom, Iran. His current research interests include quality engineering and system reliability analysis. He is the author of the papers published in the Journal of Manufacturing Systems and the Journal of Modeling in Engineering.

Faeze Mamashli is an MS student at the Department of Industrial Engineering, Faculty of Technology and Engineering, University of Qom, Qom, Iran. Her current research interests include quality engineering and multi-criterion decision-making. 